\title{
A Case Study of the Glycoside Hydrolase Enzyme Mechanism Using an Automated QM-cluster Model Building Toolkit
}

\author{
Qianyi Cheng ${ }^{1}$ and Nathan J. DeYonker ${ }^{1}$ \\ ${ }^{1}$ The University of Memphis
}

December 14, 2021

\begin{abstract}
Glycoside hydrolase enzymes are important for hydrolyzing the $\beta-1,4$ glycosidic bond in polysaccharides for deconstruction of carbohydrates. The two-step retaining reaction mechanism was explored with different sized QM-cluster models built by the Residue Interaction Network ResidUe Selector (RINRUS) software using both the wild-type protein and its E217Q mutant. The first step is the glycosylation, in which the acidic residue 217 donates a proton to the glycosidic oxygen leading to bond cleavage. In the subsequent deglycosylation step, one water molecule migrates into the active site and attacks the anomeric carbon. Residue interaction-based QM-cluster models lead to reliable structural and energetic results for proposed glycoside hydrolase mechanisms. The free energies of activation for glycosylation in the largest QM-cluster models were predicted to be 19.5 and $31.4 \mathrm{kcal} \mathrm{mol}^{-1}$ for the wild-type protein and its E217Q mutant, which agree with experimental trends that mutation of the acidic residue Glu217 to Gln will slow down the reaction, and are higher in free energy than the deglycosylation transition states (13.8 and $25.5 \mathrm{kcal} \mathrm{mol}^{-1}$ for the wild-type protein and its mutant, respectively). For the mutated protein, glycosylation led to a low-energy product. This thermodynamic sink may correspond to the intermediate state which was isolated in the X-ray crystal structure. Hence, the glycosylation is validated to be the rate-limiting step in both the wild-type and mutated enzyme. The E217Q mutation led to a higher glycosylation activation free energy that also agrees with experimental observation that mutation of E217 will slow down the reaction, but not deactivate catalysis.
\end{abstract}

\section{A Case Study of the Glycoside Hydrolase Enzyme Mechanism Using an Automated QM-cluster Model Building Toolkit}

Qianyi Cheng* and Nathan J. DeYonker*

Department of Chemistry, University of Memphis, Memphis, TN 38152, U.S.A.

E-mail: qcheng1@memphis.edu*,ndyonker@memphis.edu*

\section{ABSTRACT}

Glycoside hydrolase enzymes are important for hydrolyzing the $\beta-1,4$ glycosidic bond in polysaccharides for deconstruction of carbohydrates. The two-step retaining reaction mechanism was explored with different sized QM-cluster models built by the Residue Interaction Network ResidUe Selector (RINRUS) software using both the wild-type protein and its E217Q mutant. The first step is the glycosylation, in which the acidic residue 217 donates a proton to the glycosidic oxygen leading to bond cleavage. In the subsequent deglycosylation step, one water molecule migrates into the active site and attacks the anomeric carbon. Residue interaction-based QM-cluster models lead to reliable structural and energetic results for proposed glycoside hydrolase mechanisms. The free energies of activation for glycosylation in the largest QM-cluster models were predicted to be 19.5 and $31.4 \mathrm{kcal} \mathrm{mol}^{-1}$ for the wild-type protein and its E217Q mutant, which agree with experimental trends that mutation of the acidic residue Glu217 to Gln will slow down the reaction, and are higher in free energy than the deglycosylation transition states $\left(13.8\right.$ and $25.5 \mathrm{kcal} \mathrm{mol}^{-1}$ for the 
wild-type protein and its mutant, respectively). For the mutated protein, glycosylation led to a low-energy product. This thermodynamic sink may correspond to the intermediate state which was isolated in the X-ray crystal structure. Hence, the glycosylation is validated to be the rate-limiting step in both the wild-type and mutated enzyme. The E217Q mutation led to a higher glycosylation activation free energy that also agrees with experimental observation that mutation of E217 will slow down the reaction, but not deactivate catalysis.

\section{INTRODUCTION}

The organic biopolymer cellulose, which acts as a large source of carbohydrates, is found abundantly in the cell wall of green plants. ${ }^{1,2}$ Cellulose consists of hundreds to thousands of $\beta-1,4$ linked glucose units, which can be cleaved to form shorter chains by degradation processes. Glycoside hydrolase (GH) enzymes, as one of many enzyme classes that can modify, decompose, and assemble carbohydrates in nature, ${ }^{3}$ are responsible for breaking down the glycosidic $\beta-1,4$ linkages between $\mathrm{C}_{1}-\mathrm{O}_{4}$ via a hydrolysis reaction. Two mechanisms have been proposed for the reaction, "retaining" and "inverting" ${ }^{4}$ Utilized by many GH families, ${ }^{3}$ the retaining mechanism consists of two steps. ${ }^{5-7}$ In step one, a proton will be transferred from an acidic residue to the glycosidic oxygen $\left(\mathrm{O}_{4}\right)$, coupling with a nucleophilic attack of the anomeric carbon of the carbohydrate $\left(\mathrm{C}_{1}\right)$ forming a glycosyl-enzyme intermediate (GEI). In step two, a water molecule attacks the anomeric carbon, breaking the GEI bond and transferring a proton back to the acidic residue. These two steps are also respectively called glycosylation and deglycosylation. In the less-common inverting mechanism, proton transfer causes the cleavage of the glycosidic bond to take place via nucleophilic attack by water. ${ }^{4}$ The focus of this study will be exploring the retaining mechanism, which is utilized by many GHs, specifically GH Family 7 (GH7).

GH7 cellobiohydrolases depolymerize single chains from crystalline cellulose and hydrolyze cellobiose units from the reducing end. ${ }^{8,9} \mathrm{GH} 7$ cellobiohydrolases are major components of enzyme cocktails for biodegrading plant material ${ }^{10}$ and biofuels processes in industry. ${ }^{8}$ Therefore, numerous studies have been carried out focusing on the structures, reaction mechanisms, and energetics of GH7 cellobiohydrolases. ${ }^{8,9,11-17}$ The first structure of a cellulase was determined in 1994 from the Trichoderma reeseiextracellular cellobiohydrolase I (CBHI, $\operatorname{Tr}$ Cel7A, an anamorph of the fungus Hypocrea jecorina $).{ }^{9} \operatorname{Tr}$ Cel7A binds 10 glucosyl units $(+3$ to -7 , positive and negative numbers indicating the reducing and nonreducing end of the cellulose chain). ${ }^{18}$ It was found to catalyze the hydrolysis of the glycosidic $\beta-1,4$ linkage specifically (breaking the bond between the +1 and -1 units) in cellulose via a proposed retaining mechanism. ${ }^{19}$ This bond is difficult to hydrolyze without a catalyst, for example the free energy of activation has been measured to be $36.8 \pm 2.2$ at $\mathrm{pH} 10.6$ and $25{ }^{\circ} \mathrm{C}$ for $\beta$-methylglucopyranoside in potassium acetate, phosphate or carbonate buffers. ${ }^{19}$

The glycosyl substrate distortion in the hydrolysis of glycosides has been studied extensively. ${ }^{20,21}$ The IUPAC conventions for labelling ring conformations are used throughout. ${ }^{22}$ Large conformational change of the -1 glycose unit from the half-chair, envelope, or boat-like conformation to the ${ }^{4} C_{1}$ chair conformation is typically observed in the glycosylation step. ${ }^{20}$ This was also observed in a recent study by Beckham, Ståhlberg, Withers, Götz, et al . ${ }^{13}$ that the -1 glucose unit adopts a ${ }^{4} E$ envelope conformation in the Michaelis complex of the H. jecorina Cel7A (Hje Cel7A) E217Q mutated protein and an intact cellononaose chain (PDB: $4 \mathrm{C} 4 \mathrm{C}$ ) and $\mathrm{a}^{4} C_{1}$ chair conformation in the GEI; which was further confirmed in molecular dynamics (MD) simulations using the theoretical model of the wild-type enzyme (PDB: 8CEL, a Michaelis complex of the protein and 10 glucosyl units). The MD simulations suggested that the glucose unit changed from a half-chair $\left({ }^{4} \mathrm{H}_{5}\right)$ in the Michaelis complex to a half-chair $\left({ }^{4} \mathrm{H}_{3}\right)$ at the transition state, then to a stable chair $\left({ }^{4} C_{1}\right)$ conformation in the glycosylation product state. ${ }^{13}$ The transition state geometries were also found to be able to adopt the ${ }^{4} H_{3}$ and ${ }^{3} H_{4}$ half-chair and ${ }^{2,5} B$ and $B_{2,5}$ boat conformations. ${ }^{20,23-25}$

In an early mutation study of $\operatorname{Tr}$ Cel7A, the catalytic activities $\left(k_{\text {cat }}\right)$ were measured to be $12.8 \pm 0.2$, $0.15 \pm 0.05,0.035 \pm 0.005$, and $0.0063 \pm 0.0005 \mathrm{~min}^{-1}$ at $\mathrm{pH} 5.7$ and $37{ }^{\circ} \mathrm{C}$ for the wild-type, the $\mathrm{D} 214 \mathrm{E}$, E212Q and E217Q mutated proteins, respectively. These values correspond to a free energy of activation of $19.1 \mathrm{kcal} / \mathrm{mol}$ for the wild-type protein and $23.8 \mathrm{kcal} / \mathrm{mol}$ for the E217Q mutated protein, ${ }^{26}$ indicating the E217Q mutation slowed down the reaction. An experimental study using high-speed atomic force microscopy 
found that the rate of processive cellobiose hydrolysis by Hje Cel7A on a crystalline cellulose surface was $7.1 \pm 3.9 \mathrm{~s}^{-1}$ at $30{ }^{\circ} \mathrm{C}(16.3-17.1 \mathrm{kcal} / \mathrm{mol}) .{ }^{27} \mathrm{In}$ a more recent study comparing another GH7 from the fungus Penicillium funiculosum with $\operatorname{Tr}$ Cel7A, the $k_{\text {cat }}$ for the E217Q mutated protein was reported to be $14.26 \pm 1.05 \mathrm{~min}^{-1}$ at $\mathrm{pH}=4$ and $55{ }^{\circ} \mathrm{C}(20.2-20.3 \mathrm{kcal} / \mathrm{mol}) .{ }^{28}$ This rate constant is also slower than that of the wild-type protein.

In the study by Beckham, Ståhlberg, Withers, Götz, et al . ${ }^{13}$ the mixed quantum mechanics/molecular mechanics (QM/MM) and transition path sampling method was applied to study the full retaining catalytic mechanism starting from the Michaelis complex of theoretical model PDB:8CEL and 10 glucosyl units $(+2$ to -7 , Glc452 to Glc460) at $300 \mathrm{~K}$ and 1.0 bar. $^{13}$ The simulation results indicated that in the glycosylation step, the nucleophile Glu212, which first hydrogen bonds with Asp214, attacked the anomeric carbon $\mathrm{C}_{1}$ on the -1 position (Glc454) of glucopyranose, breaking the $\mathrm{C}_{1}-\mathrm{O}_{4}$ bond. A proton on the acidic residue Glu217 transferred to $\mathrm{O}_{4}$ on the +1 position (Glc453) of glucopyranose. In the deglycosylation step, one water enters the active site, undergoes nucleophilic attack on the -1 glycosyl unit bonding to the $\mathrm{C}_{1}$, breaks the bond between the glucopyranose and Glu212 oxygen, and lastly donates its proton to Glu217. The QM/MM computations predicted that the glycosylation was the rate limiting step with a free energy of activation of $15.5 \mathrm{kcal} \mathrm{mol}^{-1}$, and the intermediate structure was $2.5 \mathrm{kcal} \mathrm{mol}^{-1}$ lower in energy than the initial reactant. For deglycosylation, the free energy of activation of the elementary step was $11.6 \mathrm{kcal} \mathrm{mol}^{-1}$, and the final product was $2.1 \mathrm{kcal} \mathrm{mol}^{-1}$ lower in free energy than the initial reactant.

The glycosylation of GH7 (PDB: 8CEL) was later studied by the Wang group using both a pure quantum mechanics (QM) and quantum mechanics/molecular mechanics (QM/MM) approach. ${ }^{29}$ The activation free energy was computed to be $14.1 \mathrm{kcal} \mathrm{mol}^{-1}$ using a density functional theory (DFT)-based QM-cluster model at the B3LYP/6-31G(d, p) level of theory. The QM-cluster model was very small, only including residues E212, E217, +1 and -1Glc. A higher free energy glycosylation TS $\left(23.9 \mathrm{kcal} \mathrm{mol}^{-1}\right)$ was found when using $\mathrm{QM} / \mathrm{MM}$ in the same study. ${ }^{29}$ The relatively high QM/MM glycosylation barrier was explained as arising from the catalytic residues frozen in the MM-region, and this indicated that the active site environment has an important impact on the kinetics. ${ }^{29}$ In the same study, deglycosylation was examined by adding one water molecule to the QM-cluster model and a much higher free energy of activation, $32.9 \mathrm{kcal} \mathrm{mol}^{-1}$ at B3LYP/6$31 \mathrm{G}(\mathrm{d}, \mathrm{p})$ level of theory, was computed for the glycosylation. ${ }^{29}$ The results of Wang and coauthors suggest that the QM-region must be appropriately defined to obtain good agreement between experiment and theory for the GH7 enzyme.

Most early computational studies ignored deglycosylation, instead focusing on the rate-limiting glycosylation step. One full catalytic cycle was explored using a small model QM-cluster model (2 residues and the

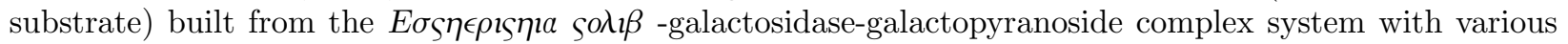
DFT functionals and basis sets and found that the glycosylation activation energies ranged from 21.1 to 28.7 $\mathrm{kcal} \mathrm{mol}{ }^{-1} \cdot{ }^{30}$ Mutational effects were also studied with QM/MD (Molecular Dynamics) simulation which predicted the glycosylation barriers to be $32.6 \mathrm{kcal} \mathrm{mol}^{-1}$ for wild-type $\operatorname{Tr}$ Cel7A. ${ }^{31}$ The following nucleophilic attack step had barriers of $0.4 \mathrm{kcal} \mathrm{mol}^{-1}$ for the elementary step. ${ }^{31}$ The glycosylation free energy barrier was computed to be $17.5 \mathrm{kcal} \mathrm{mol}^{-1}$ in a more recent DFTB/MM study on CBHI, ${ }^{32}$ and $13.4 \mathrm{kcal} \mathrm{mol}^{-1}$ in a QM/MM metadynamics study on GH27. ${ }^{33}$ Clearly, kinetics of various enzymes in the GHs family show variability, and the relationship between computational accuracy and partitioning of enzyme QM-regions needs to be explored further. The algorithmic workflow of the RINRUS toolkit provides a standard QMcluser model construction procedure, with embedded reproducibility for comparisons and benchmarking in the literature.

In this study, we use RINRUS built QM-cluster models to study the full catalytic cycle of the retaining mechanism of cellulose hydrolysis based on the wild-type protein and its E217Q mutant. The proposed mechanistic detail and energetics will provide more insights for enzyme engineering of effective catalytic modifications.

\section{COMPUTATIONAL METHODS}


Both a theoretical model of CBHI in complex with a cellulose nanomer (PDB ID: 8CEL) and the X-ray crystal structure of the Michaelis complex of Hypocrea jecorina CEL7A E217Q with cellononaose (PDB ID: 4C4C) were used to construct the models for QM-cluster computations. Hydrogen atoms were added to backbone and side chain heavy atoms of the enzyme using the reduceprogram. ${ }^{34}$ Hydrogen atoms were also manually added to the cellononaose. The active site histidine residue (His228) was doubly protonated (X-ray crystal data for $4 \mathrm{C} 4 \mathrm{C}$ is recorded at $\mathrm{pH}=6$ ). Next, the protonated PDB files were processed by probe ${ }^{35}$ to generate the Residue Interaction Networks (RINs) based on atom contact information. In the RIN of 8CEL, 23 residues (including the Glc452, Glc453, Glc454, Glc455 as the $+2,+1,-1$, and -2 glucosyl units, 16 residues, and 3 waters) were identified by RINRUS that interact with the +1 and -1 glucosyl units (named Glc +1 and Glc-1, used as the RINRUS "seed" of our models), and 17 residues among the 23 have a high interaction score (more than 50 contact dot counts). Next, 22 residues (including the Bgc1, Bgc2, Bgc3 and Bgc4 as the $+2,+1,-1,-2$ glucosyl units, 14 residues, and 4 waters) were identified in the RIN of $4 \mathrm{C} 4 \mathrm{C}$, among which 17 fragments have a $>50$ interaction count with the seed. The catalytic triad residues Glu212, Asp214 and Glu217/GLN217 in 8CEL and 4C4C which were included in the QM region in the study by Beckham, Ståhlberg, Withers, Götz, et al . ${ }^{13}$ were all identified by RINRUS as they have high contact dot counts with the -1 or +1 glucosyl units. Glu212 is the nucleophile and is positioned closely to the -1 glucose with a $\mathrm{C}_{1}$ (Glc454)-O(Glu212) bond distance of $3.44 \AA$ in $8 \mathrm{CEL}$ and $3.40 \AA$ in $4 \mathrm{C} 4 \mathrm{C}$. Glu217 and Asp214 were protonated to be neutral residues similar to the procedure in reference 13, Glu217 is the acidic residue, mutated to a protonated Gln in PDB: $4 \mathrm{C} 4 \mathrm{C}$, that donates a proton to the +1 glucosyl unit, while Asp214 hydrogen bonds to Glu212 to support the catalytic reaction. All three residues exhibit multiple conformations in the X-ray crystal structure. In Conformation A of the PDB file, Gln217 is oriented towards the glycosidic bond (similar to Glu217 in 8CEL), therefore all the QM-cluster models were built based on this conformation.

Considering the glycosylation cleavage of the $\mathrm{O}_{4}-\mathrm{C}_{1}$ bond connecting the -1 and +1 glucosyl units, only the $\mathrm{O}_{4}$ atom in the glucosyl -2 unit was kept and protonated as a hydroxyl group in the model. The +2 unit was completely removed, and one hydrogen atom was added to the $\mathrm{O}_{4}$ atom of the -1 glucosyl unit. Hence, QM-cluster models of 16 residues (227 atoms, $12{ }_{a}^{\prime \prime}$ and $10^{c} \beta$ atoms were kept frozen, namedRes16-E ) and 21 residues (the "maximal model" where all residues with nonzero contact dot counts with seed are included, 305 atoms, $19{ }^{\prime \prime}$ and $14{ }^{~ "} \beta$ atoms were kept frozen, named Res21-E ) based on the 8CEL RIN were constructed. Frozen atoms in the QM-cluster models are provided in Table 1. A model from the same 16 residue set using PDB:4C4C was built with 228 atoms (same set of frozen atoms, named Res16-Q) and a "maximal model" that included all 20 residues identified by the RIN as having interactions with the seed (275 atoms, $14^{\prime \prime}{ }_{a}$ and $9{ }^{\circ}$ atoms were kept frozen, named Res20-Q ). Residues Thr246 and Arg251 were included in the RIN of $8 \mathrm{CEL}$ but not $4 \mathrm{C} 4 \mathrm{C}$. In order to have some comparable analysis, two larger models were built by adding these residues to the 4C4C-based models (named Res21-Q which includes Arg251, and Res23-Q which includes Thr246, Arg251, and one additional water). The aligned Res21-E and Res23-Q 3D models are shown in Figure 1. The 2D structure of the Res21-Eand Res23-Q model along with frozen atom information are shown in Figure $2 \mathrm{a}$ and $2 \mathrm{~b}$. The atomic labeling for the glycosyl units is shown in Figure 2c and 2d.

All quantum mechanical cluster model computations were performed using the Gaussian16 program. ${ }^{36}$ Density functional theory (DFT) with the hybrid B3LYP exchange-correlation functional ${ }^{37,38}$ was employed with the 6-31G(d') basis set for $\mathrm{N}$, O, and $\mathrm{S}$ atoms, ${ }^{39-41}$ and the $6-31 \mathrm{G}$ basis sets for $\mathrm{C}$ and $\mathrm{H}$ atoms. ${ }^{42}$ QM-cluster models incorporated the Grimme D3 (Becke-Johnson) dispersion correction (GD3BJ) ${ }^{43,44}$ and implicit solvation via the conductor-like polarizable continuum model $(\mathrm{CPCM})^{45,46}$ using universal force field (UFF) atomic radii, a non-default electrostatic scaling factor of 1.2, and the default parameters for water with an attenuated dielectric constant of $\varepsilon=4$. This dielectric constant value has been previously determined as appropriate for simulating the less-polarized environment within an enzyme active site. ${ }^{47,48}$ Unscaled harmonic vibrational frequency calculations were used to identify all stationary points as either minima (no imaginary frequencies) or transition states (TSs, only one imaginary frequency). TSs were located first for each elementary step of the proposed mechanism; the reactants and products were then located by following 
the intrinsic reaction coordinate (IRC). ${ }^{49,50}$ It is important to note that our group uses the "freeze code" scheme in Gaussian16, where all Hessian elements are zero when involving frozen internal coordinates. The phenomenon where several small magnitude imaginary vibrational frequencies appear in the thermochemical analysis does not arise in our treatment of the Hessian matrix. Zero-point energies (ZPE) and thermal enthalpy/free energy corrections were computed at $1 \mathrm{~atm}$ and $310 \mathrm{~K}$.

\section{RESULTS AND DISCUSSION}

The labeling scheme ResV-W(X)-YZ is used for the QM-cluster model illustrating the reaction mechanism, where $\mathbf{V}=$ \# of residues in the model $(16,20,21$ or 23); $\mathbf{W}=\mathrm{E}$ for residue E217 in the wild-type protein (8CEL) or Q for residue Q217 in the mutated protein $(4 \mathrm{C} 4 \mathrm{C})$; $\mathbf{X}$ indicates when multiple conformations (A, $\mathbf{B}$ or $\mathbf{C}$ ) are explored and reported; $\mathbf{Y}=\mathrm{R}$ (reactant), TS (transition state), Int (intermediate state), or $\mathrm{P}$ (product); $\mathbf{Z}=1$ indicates glycosylation, $\mathbf{Z}=2$ indicates deglycosylation. For example, Res16-EA-R1 refers to the optimized 16-residue glycosylation reactant with residue E217 (8CEL) in conformation A, which is the lowest energy reactant.

\section{Step 1: Glycosylation}

The representative reactants, transition states (TS), and products of the glycosylation reaction step are shown in Figures 3 and 4, which use the maximal model Res21-E and Res23-Q generated from the wildtype protein theoretical model (8CEL) and its E212Q mutant X-ray crystal structure (4C4C). The reactant is a Michaelis complex and the glycosidic bond $\left(\mathrm{O}_{4}-\mathrm{C}_{1}\right)$ between Glc +1 and Glc-1 is intact. Glu217/Gln217 is protonated, and the proton is hydrogen bonding with $\mathrm{O}_{4}$ of Glc+1. In the TS, the proton of Glu217/Gln217 is transferred between the $\mathrm{O}_{4}$ of Glc+1 and sidechain oxygen atom of Glu217 or nitrogen atom of Glu217. While the glycosidic bond is elongated and the Glc- 1 ring distorts from a ${ }^{4} E$ envelope conformation in the reactant to $\mathrm{a}^{4} \mathrm{H}_{3}$ half chair conformation, the anomeric $\mathrm{C}_{1}$ shifts close to Glu212 (Figure 5). Sidechain rotations are observed in Glu212, Asp214 and Glu217/Gln217 as well as sidechain shifts in the aromatic residues Tyr145 and Trp367 close to Glc- 1 and Trp376 above Glc+1. In the product, the glycosidic bond is broken as the proton is transferred to the glycosidic $\mathrm{O}_{4}$, while $\mathrm{C}_{1}$ migrates closer to Glu212 and the Glc-1 glycosyl ring distorts to $\mathrm{a}^{4} C_{1}$ chair-like conformation. In this step, the Glc+1 glycosyl ring migrates away from Glc-1 without large conformational change. The geometric parameters for the optimized reactants, TSs, and products for different models can be found in Table S1.

The free energy diagram for glycosylation is shown in Figure 6. The free energies of activation using Res16E and Res21-Emodels are computed to be 15.5 and $19.5 \mathrm{kcal} / \mathrm{mol}$. Similarly to the energy of the earlier computational study using the $\mathrm{QM} / \mathrm{MM}+$ potential of mean force free energy sampling, our free energy of activation in glycosylation using the smaller model is close to the experimentally measured kinetics, while the result using the lager model is in excellent agreement with the activation free energy (19.11 $19.13 \mathrm{kcal} / \mathrm{mol})$ derived from the experimentally measured rate constants $\left[k_{c a t}=12.8( \pm 0.2) \mathrm{min}^{-1}\right]$ at 37 ${ }^{o} \mathrm{C} .{ }^{26}$ Our two models of $8 \mathrm{CEL}$ lead to glycosylation products that are 10.8 and $7.0 \mathrm{kcal} / \mathrm{mol}$ higher in free energy than their corresponding reactants. Using the QM-cluster models based on the E217Q mutated 4C4C X-ray crystal structure, the activation free energies of glycosylation are computed to be 28.2, 34.6, and $30.4 \mathrm{kcal} / \mathrm{mol}$ for Res16-Q, Res20-Q, and Res21-Q , respectively; and $31.4 \mathrm{kcal} / \mathrm{mol}$ using the maximal RINRUS modelRes23-Q , which is $7 \mathrm{kcal} / \mathrm{mol}$ higher than the free energy $(22.68-22.85 \mathrm{kcal} / \mathrm{mol})$ converted from the experimentally measured rate constants $\left[k_{c a t}=3.5( \pm 0.5) \times 10^{-2} \mathrm{~min}^{-1}\right]{ }^{26}$ Addition of a water molecule plus Thr246 and Arg251 residues causes the Glc +1 ring to shift less from Glc- $1\left(\mathrm{C}_{1}-\mathrm{O}_{4}\right.$ bond length is $2.31 \mathrm{~A}$ in Res23-Q-TS versus $2.91 \mathrm{~A}$ in Res20-Q-TS ). All models of the E217Q mutated protein led to glycosylation products that are higher in free energy compared to their corresponding reactant. Clearly, the E217Q mutation is much less kinetically or thermodynamically favored for glycosylation. This nicely corresponds to the hypothesis that the E217Q should destabilize the glycosylation transition state.

The predicted free energy of activation for the glycosylation step of the mutated protein is concerningly higher than experimentally measured kinetics value. However, our QM-cluster model kinetics are still more qualitatively reasonable than some previous Cel7A QM/MM-based models. Disagreement between exper- 
iment and theory for the E217Q glycosylation activation free energy may be rationalized by frozen atoms exacerbating the already poor proton donating ability of the Gln217 residue. Alternatively, we may not have exhaustively explored glycosyl ring distortions that may provide further transition state stabilization. Lastly, the somewhat coarse level of electronic structure theory used in our QM-cluster models will always cause some deviation from experimental kinetic and thermodynamic values.

\section{Step 2: Deglycosylation}

One explicit water molecule is added to the active site models for the deglycosylation path, so that the deglycosylation reactant can be connected to the glycosylation product. The representative reactants, transition states (TS), and products of the deglycosylation reaction step are shown in Figures 7 and 8, which use models Res21-E andRes23-Q . In the reactant, the water positions its oxygen close to the $\mathrm{C}_{1}$ of Glc-1, but opposite to Glu212. While one of the hydrogen atoms is close to Glu217-O/Gln217-N, the other hydrogen bonds to the glycosidic $\mathrm{O}_{4}$ of Glc +1 and pushes the Glc+1 further away from Glc-1 compared to the glycosylation product. In the TS, Glc-1 shifts slightly towards the water but further away from Glu212, while the water shifts slightly coupled with sidechain rotation in Glu217/Gln217. A proton transfer from the new water molecule couples with the water nucleophilic attack $\mathrm{C}_{1}$ of Glc-1 in the TS. The proton from the water transfers to Glu217-O/Gln217-N, and the $\mathrm{OH}$ group bonds to $\mathrm{C}_{1}$ of Glc-1, leading to the glycosyl unit migrating further away from Glu212. The glycosyl unit Glc-1 again undergoes a large conformational change from ${ }^{4} C_{1}$ to $^{4} H_{3}$ to ${ }^{4} E$ (Figure 9), which is opposite from the glycosylation process. Most of the residues of the reactant, TS, and product in deglycosylation are structurally unperturbed, while large geometric changes are seen in Trp376 and Trp367, which are near the glycosyl units, and Tyr145, which is close to the Glc-1 glycosyl unit. The geometric parameters for the optimized reactants, TSs, and products of deglycosylation for different QM-cluster models can be found in Table S2.

The free energy diagram of deglycosylation is also shown in Figure 6 and Table S3. The deglycosylation reactant is lower in energy than the glycosylation reactant in Res16-E model, but higher than the glycosylation reactant in other models. The deglycosylation free energies of activation using the Res16-E and Res21-Emodels are computed to be 23.9 and $13.8 \mathrm{kcal} / \mathrm{mol}(14.1$ and $1.9 \mathrm{kcal} / \mathrm{mol}$ for this elementary step) and the corresponding products are found to be $3.4 \mathrm{kcal} / \mathrm{mol}$ higher and $0.9 \mathrm{kcal} / \mathrm{mol}$ lower in free energy than the glycosylation reactant. The free energy of activation for deglycosylation of the mutated models Res16-QA ,Res20-QA, Res21-QA and Res23-QA are 1.5, 1.7, 0.7, and $1.3 \mathrm{kcal} / \mathrm{mol}$ for the elementary step, but much higher in overall free energy of activation $(34.9,30.0,25.5$ and $31.0 \mathrm{kcal} / \mathrm{mol})$. Similar to Res21-EA model, whose deglycosylation reactant is $5.0 \mathrm{kcal} / \mathrm{mol}$ higher than the glycosylation product plus one water, all these E217Q mutated models have deglycosylation reactants $20.9,4.9,6.4$, and $11.52 \mathrm{kcal} / \mathrm{mol}$ higher in free energy than glycosylation products plus water. Comparing the both maximal models, the larger energy difference between the glycosylation product and deglycosylation reactant seen in the mutated model Res23-QA may explain the observation of a GEI in the X-ray crystal structure (PDB 4C4C).

Overall, in the RINRUS models of the wild-type protein, the glycosylation transition state is found to be the rate limiting step in our proposed mechanism. While the deglycosylation step in the mutated enzyme has a very high free energy of activation and is competitive with glycosylation, it is still slightly lower in free energy than the TS of the glycosylation step. The glycosylation of the mutant is slower than the wild-type enzyme, which agrees well with experimental observation.

\section{Alternative reactant conformations of the glycosylation and deglycosylation steps}

For the glycosylation step, using the RINRUS-derived models (Res16-E and Res21-E ) of the theoretical protein 8CEL enabled us to explore different conformations. Conformational differences (Figure S1) are seen in the sidechains of the aromatic residues Tyr145, His228, Trp367, and Trp376 which surround the glycosyl units, Asp214 which hydrogen bonds to the important residue Glu212, and Asp173 and water molecules which form hydrogen bonds with the glycosyl units. The Glu217 sidechain is also quite flexible and can adopt multiple conformations in our QM-cluster models. The free energy diagram of glycosylation using different conformers is shown in Figure 10. Note that the Res16-EA and Res21-EA models discussed here 
are shown in Figure 6 and previously discussed. BothRes16-EB-R1 and Res21-EB-R1 are slightly higher in energy than Res16-EA-R1 and Res21-EA-R1 but lead to a higher energy TS, which indicates that the glycosylation will be unlike to take place via conformation B. The free energy of activation for models Res16-EC is slightly higher than that ofRes16-EA, and reactant Res16-EC-R1 is $6.5 \mathrm{kcal} / \mathrm{mol}$ higher in free energy than Res16-EA-R1, which indicates that the glycosylation reaction will be more likely to occur via conformationA. While for the maximal model, even thoughRes21-EC-R1 is $4.3 \mathrm{kcal} / \mathrm{mol}$ higher in energy thanRes21-EA-R1, the Res21-EC model has a lower free glycosylation activation energy than that of Res21-EA. Hence, the deglycosylation was examined and a much higher energy TS was located which indicates that reaction will be unlikely to take place via conformation C.

Three conformations of models Res20-Q and Res21-Qbased on the mutated protein are found in the glycosylation step and the free energy diagram is shown in Figure 11. The glycosylation reactants in the three conformations have different Trp367 and Trp376 sidechain orientations (Figure S2b and S2c); and the reactants in conformationB and $\mathrm{C}$ are less than $4.5 \mathrm{kcal} / \mathrm{mol}$ higher in free energy than the reactants in conformation A . However, the activation free energies of glycosylation of conformation B (28.2 and $26.5 \mathrm{kcal} / \mathrm{mol}$ forRes20-QB and Res21-QB ) are lower than those in conformation A, the corresponding free energy of activation for deglycosylation were computed to be 40.5 and $43.3 \mathrm{kcal} / \mathrm{mol}$ forRes20-QB and Res21-QB , respectively, which indicates that even if conformation $\mathbf{B}$ of the mutated protein is more kinetically favorable for glycosylation, the free energies of activation for deglycosylation are too high to be catalytically viable. These large energy differences in the two steps could be caused by one water shifting to a position close to Glc+1, which blocked Glc+1 from moving away from Glc-1. This water reorientation makes it difficult for the additional water to attack the anomeric carbon. In bothRes20-QC and Res21-QC models, the free energies of TSs are competitive compared to conformer A, but Res20-QC-R1 andRes21QC-R1 are 1.7 and $0.2 \mathrm{kcal} / \mathrm{mol}$ higher thanRes20-QA-R1 and Res21-QA-R1 and the glycosylation products of both conformer $\mathrm{C}$ are higher in energy than those of conformer $\mathrm{A}$, which may lead to a similar deglycosylation reactant in conformer A.

Multiple conformations of Res16-Q and Res23-Q are located for both glycosylation and deglycosylation. The free energy diagrams of both models are shown in Figure 12. The reactants, TS, and products in glycosylation step are very similar in Res16-QA andRes16-QB models; only small differences are seen in Trp367, Trp376 and waters. Both conformers have very high energy deglycosylation TSs, indicating that larger QM-cluster models are needed to study the reactions of GHs. Three conformations of the maximal model are examined. Like Res20-Q and Res21-Q, the TS in the three additional conformations have almost the same free energy, even though the reactants of Res23-QB and Res23-QC are 6.4 and $3.5 \mathrm{kcal} / \mathrm{mol}$ higher than Res23-QA-R1. For conformer B the deglycosylation has a very high energy TS, indicating the reaction is unlikely to take place via this conformation. The product of conformer $\mathbf{C}$ is also higher in free energy than that of conformer A . Overall, conformation $\mathbf{A}$ is the most energetically favored.

\section{Conclusions}

Cellulose hydrolysis by the cellobiohydrolase enzyme via a two-step retaining process is elucidated by two QM-cluster models built on the wild-type theoretical protein structure PDB:8CEL and four models built on the X-ray crystal structure PDB:4C4C in which Glu217 is mutated to Gln. In the glycosylation step, a proton from residue 217 is transferred to the glycosyl unit coupled with the glycosidic bond cleavage. Large conformational change is observed in the Glc-1 unit in both the wild-type and mutated enzyme models. The catalytic trio Glu212, Asp214 and Glu217/Gln217 are important for the reaction. Mutation of Glu to Gln leads to a weaker proton donor that increases the free energy of activation in both glycosylation and deglycosylation. These three residues are also quite flexible as multiple sidechain orientations are seen in the X-ray crystal structure as well as in the multiple pathways proposed in our study. In the deglycosylation step, one explicit water molecule is added to the models and the free energy of activation is lower than those in the glycosylation step in the wild-type protein, indicating glycosylation is the rate-limiting step. The deglycosylation step of the mutated protein model becomes more competitive kinetically. Large QM-cluster models (Res21-EA, Res20-QA, Res21-QA, and Res23-QA) lead to a low energy deglycosylation 
product, hence the full catalytic cycle is thermodynamically favored.

The RINs based on 8CEL and 4C4C are slightly different. However, the fringe residues Arg251 and Thr246, which have fewer interaction counts with the glycosyl units are found to have minor effect on the kinetics of the proposed mechanisms. The free energy of activation of glycosylation is only lowered by $1.5 \mathrm{kcal} / \mathrm{mol}$ when adding Arg251 toRes20-QA (to form Res21-QA) ; the glycosylation activation free energy is lowered by $3.0 \mathrm{kcal} / \mathrm{mol}$ when adding Thr246 and one water to Res21-QA (to form Res23-QA ). All RINRUSbuilt models provide free energies of activation for the glycosylation step which are in good agreement with experimental measurements of $k_{c a t}$ values for the wild-type protein and its E217Q mutant. Enzymatic reaction studies based on the residue interaction network and QM-cluster models automatically generated by RINRUS can provide good structural and energetic results for better understanding of enzyme reaction mechanisms. The RINRUS workflow is inherently reproducible, which will be greatly beneficial to the computational enzymology community.

\section{AUTHOR INFORMATION}

Qianyi Cheng - Department of Chemistry, University of Memphis, Memphis, Tennessee, 38152

Nathan J. DeYonker- Department of Chemistry, University of Memphis, Memphis, Tennessee, 38152

\section{ACKNOWLEDGEMENTS}

This work was supported by the National Science Foundation (CAREER) BIO-1846408 and

DOE BES SBIR DE-SC0021568. The High-Performance Computing Center and the Computational Research on Materials Institute at The University of Memphis (CROMIUM) also provided generous resources for this research. The authors also thank Gregg Beckham, Heather Mayes, and Brandon Knott (NREL) for assistance.

References:

(1) Klemm, D.; Heublein, B.; Fink, H.-P.; Bohn, A. Cellulose: Fascinating Biopolymer and Sustainable Raw Material. Angew. Chemie Int. Ed. 2005 , 44 (22), 3358-3393. https://doi.org/10.1002/anie.200460587.

(2) Updegraff, D. M. Semimicro Determination of Cellulose Inbiological Materials. Anal. Biochem. 1969 , 32 (3), 420-424. https://doi.org/10.1016/S0003-2697(69)80009-6.

(3) Cantarel, B. L.; Coutinho, P. M.; Rancurel, C.; Bernard, T.; Lombard, V.; Henrissat, B. The Carbohydrate-Active EnZymes Database (CAZy): An Expert Resource for Glycogenomics. Nucleic Acids Res.2009 , 37 (Database), D233-D238. https://doi.org/10.1093/nar/gkn663.

(4) KOSHLAND, D. E. STEREOCHEMISTRY AND THE MECHANISM OF ENZYMATIC REACTIONS. Biol. Rev. 1953, 28 (4), 416-436. https://doi.org/10.1111/j.1469-185X.1953.tb01386.x.

(5) Gerlind Sulzenbacher; Schulein, M.; Davies, G. J. Structure of the Endoglucanase I from Fusarium Oxysporum: Native, Cellobiose, and 3,4-Epoxybutyl $\beta$-d-Cellobioside-Inhibited Forms, at $2.3 \AA$ Resolution.1997 . https://doi.org/10.1021/BI962963+.

(6) MACKENZIE, L. F.; SULZENBACHER, G.; DIVNE, C.; JONES, T. A.; WÖLDIKE, H. F.; SCHÜLEIN, M.; WITHERS, S. G.; DAVIES, G. J. Crystal Structure of the Family 7 Endoglucanase I (Cel7B) from Humicola Insolens at $2.2 \AA$ Resolution and Identification of the Catalytic Nucleophile by Trapping of the Covalent Glycosyl-Enzyme Intermediate. Biochem. J. 1998 , 335 (2), 409-416. https://doi.org/10.1042/bj3350409.

(7) Davies, G. J.; Mackenzie, L.; Varrot, A.; Dauter, M.; Brzozowski, A. M.; Schülein, M.; Withers, S. G. Snapshots along an Enzymatic Reaction Coordinate: Analysis of a Retaining $\beta$-Glycoside Hydrolase.Biochemistry 1998, 37 (34), 11707-11713. https://doi.org/10.1021/bi981315i.

(8) Chundawat, S. P. S.; Beckham, G. T.; Himmel, M. E.; Dale, B. E. Deconstruction of Lignocellulosic Biomass to Fuels and Chemicals.Annu. Rev. Chem. Biomol. Eng. 2011 , 2 (1), 121-145. 
https://doi.org/10.1146/annurev-chembioeng-061010-114205.

(9) Divne, C.; Ståhlberg, J.; Reinikainen, T.; Ruohonen, L.; Pettersson, G.; Knowles, J. K. C.; Teeri, T. T.; Jones, T. A. The Three-Dimensional Crystal Structure of the Catalytic Core of Cellobiohydrolase I from Trichoderma Reesei. Science (80-. ). 1994, 265(5171), 524-528. https://doi.org/10.1126/science.8036495.

(10) Martinez, D.; Berka, R. M.; Henrissat, B.; Saloheimo, M.; Arvas, M.; Baker, S. E.; Chapman, J.; Chertkov, O.; Coutinho, P. M.; Cullen, D.; Danchin, E. G. J.; Grigoriev, I. V; Harris, P.; Jackson, M.; Kubicek, C. P.; Han, C. S.; Ho, I.; Larrondo, L. F.; de Leon, A. L.; Magnuson, J. K.; Merino, S.; Misra, M.; Nelson, B.; Putnam, N.; Robbertse, B.; Salamov, A. A.; Schmoll, M.; Terry, A.; Thayer, N.; WesterholmParvinen, A.; Schoch, C. L.; Yao, J.; Barabote, R.; Nelson, M. A.; Detter, C.; Bruce, D.; Kuske, C. R.; Xie, G.; Richardson, P.; Rokhsar, D. S.; Lucas, S. M.; Rubin, E. M.; Dunn-Coleman, N.; Ward, M.; Brettin, T. S. Genome Sequencing and Analysis of the Biomass-Degrading Fungus Trichoderma Reesei (Syn. Hypocrea Jecorina). Nat. Biotechnol. 2008 , 26 (5), 553-560. https://doi.org/10.1038/nbt1403.

(11) Divne, C.; Ståhlberg, J.; Teeri, T. T.; Jones, T. A. High-Resolution Crystal Structures Reveal How a Cellulose Chain Is Bound in the $50 \AA$ Long Tunnel of Cellobiohydrolase I from Trichoderma Reesei 1 1Edited by K. Nagai. J. Mol. Biol. 1998 , 275 (2), 309-325. https://doi.org/10.1006/jmbi.1997.1437.

(12) Kern, M.; McGeehan, J. E.; Streeter, S. D.; Martin, R. N. A.; Besser, K.; Elias, L.; Eborall, W.; Malyon, G. P.; Payne, C. M.; Himmel, M. E.; Schnorr, K.; Beckham, G. T.; Cragg, S. M.; Bruce, N. C.; McQueen-Mason, S. J. Structural Characterization of a Unique Marine Animal Family 7 Cellobiohydrolase Suggests a Mechanism of Cellulase Salt Tolerance. Proc. Natl. Acad. Sci. 2013 , 110 (25), 10189-10194. https://doi.org/10.1073/pnas.1301502110.

(13) Knott, B. C.; Haddad Momeni, M.; Crowley, M. F.; Mackenzie, L. F.; Götz, A. W.; Sandgren, M.; Withers, S. G.; Ståhlberg, J.; Beckham, G. T. The Mechanism of Cellulose Hydrolysis by a Two-Step, Retaining Cellobiohydrolase Elucidated by Structural and Transition Path Sampling Studies. J. Am. Chem. Soc. 2014 , 136 (1), 321-329. https://doi.org/10.1021/ja410291u.

(14) Knott, B. C.; Crowley, M. F.; Himmel, M. E.; Ståhlberg, J.; Beckham, G. T. Carbohydrate-Protein Interactions That Drive Processive Polysaccharide Translocation in Enzymes Revealed from a Computational Study of Cellobiohydrolase Processivity. J. Am. Chem. Soc.2014 , 136 (24), 8810-8819. https://doi.org/10.1021/ja504074g.

(15) Bu, L.; Beckham, G. T.; Shirts, M. R.; Nimlos, M. R.; Adney, W. S.; Himmel, M. E.; Crowley, M. F. Probing Carbohydrate Product Expulsion from a Processive Cellulase with Multiple Absolute Binding Free Energy Methods. J. Biol. Chem. 2011 , 286 (20), 18161-18169. https://doi.org/10.1074/jbc.M110.212076.

(16) Vermaas, J. V.; Crowley, M. F.; Beckham, G. T.; Payne, C. M. Effects of Lytic Polysaccharide Monooxygenase Oxidation on Cellulose Structure and Binding of Oxidized Cellulose Oligomers to Cellulases. $J$. Phys. Chem. B 2015 , 119 (20), 6129-6143. https://doi.org/10.1021/acs.jpcb.5b00778.

(17) Knott, B. C.; Erickson, E.; Allen, M. D.; Gado, J. E.; Graham, R.; Kearns, F. L.; Pardo, I.; Topuzlu, E.; Anderson, J. J.; Austin, H. P.; Dominick, G.; Johnson, C. W.; Rorrer, N. A.; Szostkiewicz, C. J.; Copié, V.; Payne, C. M.; Woodcock, H. L.; Donohoe, B. S.; Beckham, G. T.; McGeehan, J. E. Characterization and Engineering of a Two-Enzyme System for Plastics Depolymerization. Proc. Natl. Acad. Sci.2020 , 117 (41), 25476-25485. https://doi.org/10.1073/pnas.2006753117.

(18) DAVIES, G. J.; WILSON, K. S.; HENRISSAT, B. Nomenclature for Sugar-Binding Subsites in Glycosyl Hydrolases. Biochem. J.1997 , 321 (2), 557-559. https://doi.org/10.1042/bj3210557.

(19) Wolfenden, R.; Lu, X.; Young, G. Spontaneous Hydrolysis of Glycosides. J. Am. Chem. Soc. 1998 , 120 (27), 6814-6815. https://doi.org/10.1021/ja9813055.

(20) Vocadlo, D. J.; Davies, G. J. Mechanistic Insights into Glycosidase Chemistry. Curr. Opin. Chem. Biol. 2008 , 12 (5), 539-555. https://doi.org/10.1016/j.cbpa.2008.05.010. 
(21) Mayes, H. B.; Broadbelt, L. J.; Beckham, G. T. How Sugars Pucker: Electronic Structure Calculations Map the Kinetic Landscape of Five Biologically Paramount Monosaccharides and Their Implications for Enzymatic Catalysis. J. Am. Chem. Soc. 2014 , 136(3), 1008-1022. https://doi.org/10.1021/ja410264d.

(22) Conformational Nomenclature for Five and Six-Membered Ring Forms of Monosaccharides and Their Derivatives. Recommendations 1980. Eur. J. Biochem. 1980 , 111 (2), 295-298. https://doi.org/10.1111/j.1432-1033.1980.tb04941.x.

(23) Davies, G. J.; Ducros, V. M.-A.; Varrot, A.; Zechel, D. L. Mapping the Conformational Itinerary of $\beta$-Glycosidases by X-Ray Crystallography.Biochem. Soc. Trans. 2003 , 31 (3), 523-527. https://doi.org/10.1042/bst0310523.

(24) Satoh, H.; Manabe, S. Design of Chemical Glycosyl Donors: Does Changing Ring Conformation Influence Selectivity/Reactivity? Chem. Soc. Rev. 2013 , 42 (10), 4297. https://doi.org/10.1039/c3cs35457a.

(25) Cremer, D.; Pople, J. A. General Definition of Ring Puckering Coordinates. J. Am. Chem. Soc. 1975 , 97 (6), 1354-1358. https://doi.org/10.1021/ja00839a011.

(26) Ståhlberg, J.; Divne, C.; Koivula, A.; Piens, K.; Claeyssens, M.; Teeri, T. T.; Jones, T. A. Activity Studies and Crystal Structures of Catalytically Deficient Mutants of Cellobiohydrolase I FromTrichoderma Reesei. J. Mol. Biol. 1996 , 264 (2), 337-349. https://doi.org/10.1006/jmbi.1996.0644.

(27) Igarashi, K.; Uchihashi, T.; Koivula, A.; Wada, M.; Kimura, S.; Okamoto, T.; Penttilä, M.; Ando, T.; Samejima, M. Traffic Jams Reduce Hydrolytic Efficiency of Cellulase on Cellulose Surface. Science (80-. ). 2011 , 333 (6047), 1279-1282. https://doi.org/10.1126/science.1208386.

(28) Taylor, L. E.; Knott, B. C.; Baker, J. O.; Alahuhta, P. M.; Hobdey, S. E.; Linger, J. G.; Lunin, V. V.; Amore, A.; Subramanian, V.; Podkaminer, K.; Xu, Q.; VanderWall, T. A.; Schuster, L. A.; Chaudhari, Y. B.; Adney, W. S.; Crowley, M. F.; Himmel, M. E.; Decker, S. R.; Beckham, G. T. Engineering Enhanced Cellobiohydrolase Activity.Nat. Commun. 2018 , 9 (1), 1186. https://doi.org/10.1038/s41467-018-03501-8.

(29) Li, J.; Du, L.; Wang, L. Glycosidic-Bond Hydrolysis Mechanism Catalyzed by Cellulase Cel7A from Trichoderma Reesei: A Comprehensive Theoretical Study by Performing MD, QM, and QM/MM Calculations. J. Phys. Chem. B 2010 , 114 (46), 15261-15268. https://doi.org/10.1021/jp1064177.

(30) Brás, N. F.; Moura-Tamames, S. A.; Fernandes, P. A.; Ramos, M. J. Mechanistic Studies on the Formation of Glycosidase-Substrate and Glycosidase-Inhibitor Covalent Intermediates. J. Comput. Chem.2008 , 29 (15), 2565-2574. https://doi.org/10.1002/jcc.21013.

(31) Yan, S.; Li, T.; Yao, L. Mutational Effects on the Catalytic Mechanism of Cellobiohydrolase I from Trichoderma Reesei. J. Phys. Chem. B 2011 , 115 (17), 4982-4989. https://doi.org/10.1021/jp200384m.

(32) Barnett, C. B.; Wilkinson, K. A.; Naidoo, K. J. Molecular Details from Computational Reaction Dynamics for the Cellobiohydrolase I Glycosylation Reaction. J. Am. Chem. Soc. 2011 ,133 (48), 19474-19482. https://doi.org/10.1021/ja206842j.

(33) Pan, X.-L.; Liu, W.; Liu, J.-Y. Mechanism of the Glycosylation Step Catalyzed by Human $\alpha$ Galactosidase: A QM/MM Metadynamics Study. J. Phys. Chem. B 2013 , 117 (2), 484-489. https://doi.org/10.1021/jp308747c.

(34) Word, J. M.; Lovell, S. C.; Richardson, J. S.; Richardson, D. C. Asparagine and Glutamine: Using Hydrogen Atom Contacts in the Choice of Side-Chain Amide Orientation 1 1Edited by J. Thornton. J. Mol. Biol. 1999 , 285 (4), 1735-1747. https://doi.org/10.1006/jmbi.1998.2401.

(35) Word, J. M.; Lovell, S. C.; LaBean, T. H.; Taylor, H. C.; Zalis, M. E.; Presley, B. K.; Richardson, J. S.; Richardson, D. C. Visualizing and Quantifying Molecular Goodness-of-Fit: Small-Probe Contact Dots with Explicit Hydrogen Atoms 1 1Edited by J. Thornton. J. Mol. Biol.1999 , 285 (4), 1711-1733. https://doi.org/10.1006/jmbi.1998.2400. 
(36) Frisch, M. J.; Trucks, G. W.; Schlegel, H. B.; Scuseria, G. E.; Robb, M. A.; Cheeseman, J. R.; Scalmani, G.; Barone, V.; Petersson, G. A.; Nakatsuji, H.; et al. Gaussian 16 Revision B.01. 2016.

(37) Lee, C.; Yang, W.; Parr, R. G. Development of the Colle-Salvetti Correlation-Energy Formula into a Functional of the Electron Density.Phys. Rev. B 1988 , 37 (2), 785-789. https://doi.org/10.1103/PhysRevB.37.785.

(38) Becke, A. D. Density-Functional Thermochemistry. \{III. The\} Role of Exact Exchange. J. Chem. Phys. $1993,98,5648-5652$.

(39) Hariharan, P. C.; Pople, J. A. The Influence of Polarization Functions on Molecular Orbital Hydrogenation Energies. Theor. Chim. Acta 1973 , 28 (3), 213-222. https://doi.org/10.1007/BF00533485.

(40) Petersson, G. A.; Al-Laham, M. A. A Complete Basis Set Model Chemistry. II. Open-Shell Systems and the Total Energies of the First-Row Atoms. J. Chem. Phys. 1991 , 94 (9), 6081-6090. https://doi.org/10.1063/1.460447.

(41) Foresman, J. B.; Frisch, Æ. Exploring Chemistry with Electronic Structure Methods (2nd Ed.). Pittsburgh, PA: Gaussian Inc. 1996, pp 266, 278-283.

(42) Hehre, W. J.; Ditchfield, R.; Pople, J. A. Self-Consistent Molecular Orbital Methods. XII. Further Extensions of Gaussian - Type Basis Sets for Use in Molecular Orbital Studies of Organic Molecules.J. Chem. Phys. 1972 , 56 (5), 2257-2261. https://doi.org/10.1063/1.1677527.

(43) Grimme, S.; Ehrlich, S.; Goerigk, L. Effect of the Damping Function in Dispersion Corrected Density Functional Theory. J. Comput. Chem. 2011, 32 (7), 1456-1465. https://doi.org/10.1002/jcc.21759.

(44) Grimme, S.; Antony, J.; Ehrlich, S.; Krieg, H. A Consistent and Accurate Ab Initio Parametrization of Density Functional Dispersion Correction (DFT-D) for the 94 Elements H-Pu. J. Chem. Phys.2010 , 132 (15), 154104. https://doi.org/10.1063/1.3382344.

(45) Barone, V.; Cossi, M. Quantum Calculation of Molecular Energies and Energy Gradients in Solution by a Conductor Solvent Model. J. Phys. Chem. A 1998 , 102 (11), 1995-2001. https://doi.org/10.1021/jp9716997.

(46) Cossi, M.; Rega, N.; Scalmani, G.; Barone, V. Energies, Structures, and Electronic Properties of Molecules in Solution with the C-PCM Solvation Model. J. Comput. Chem. 2003 , 24 (6), 669-681. https://doi.org/10.1002/jcc.10189.

(47) Siegbahn, P. E. M.; Blomberg, M. R. A. Transition-Metal Systems in Biochemistry Studied by High-Accuracy Quantum Chemical Methods.Chem. Rev. 2000 , 100 (2), 421-438. https://doi.org/10.1021/cr980390w.

(48) Blomberg, M. R. A.; Borowski, T.; Himo, F.; Liao, R.-Z.; Siegbahn, P. E. M. Quantum Chemical Studies of Mechanisms for Metalloenzymes.Chem. Rev. 2014 , 114 (7), 3601-3658. https://doi.org/10.1021/cr400388t.

(49) Fukui, K. Formulation of the Reaction Coordinate. J. Phys. Chem. 1970 , 74 (23), 4161-4163. https://doi.org/10.1021/j100717a029.

(50) Fukui, K. The Path of Chemical Reactions - the IRC Approach.Acc. Chem. Res. 1981 , 14 (12), 363-368. https://doi.org/10.1021/ar00072a001.

Table 1. Residue and trimming information for the various QM-cluster models built in this study. "a " indicates frozen alpha-carbon atoms for that residue, " " $a$ " $\beta$ " indicates frozen alpha- and beta-carbons for that residue, " $\mathrm{X}$ " indicates the specified non-amino acid residue fragment is included in the model. Residues ID\#s written in italics were not identified in the RIN as interacting with the seed, but were added as bridging residues connecting two discrete residues. 


\begin{tabular}{|c|c|c|c|c|c|c|c|c|}
\hline & Residue Name & & Res16-E & Res21-E & Res16-Q & Res20-Q & Res21-Q & Res23-Q \\
\hline \multirow{4}{*}{1} & \multirow[t]{2}{*}{ \# of Atoms } & & 227 & 305 & 228 & 275 & 297 & 312 \\
\hline & & Charge & 0 & 0 & 0 & -1 & 0 & 0 \\
\hline & Ala143 & 0 & & ${ }_{a}^{a}{ }_{a}^{\prime \prime} \beta$ & & ${ }_{a}^{\prime \prime}{ }^{\prime \prime} \beta$ & ${ }_{a}^{\prime} a{ }^{\prime} \beta$ & ${ }^{a}{ }_{a}{ }^{\prime} \beta$ \\
\hline & Leu144 & 0 & & a & & $a$ & a & $a^{\prime}$ \\
\hline 2 & Tyr145 & 0 & ${ }_{a}^{\prime \prime}{ }_{a}^{\prime \prime} \beta$ & ${ }_{a}^{a} c^{\prime \prime}$ & ${ }_{a}^{\prime \prime}{ }^{\prime \prime}$ & ${ }_{a}^{\prime \prime}{ }^{\prime \prime} \beta$ & ${ }_{a}^{\prime \prime}{ }_{\beta}^{\prime \prime}$ & ${ }^{\prime \prime}{ }_{\alpha}^{\prime \prime}$ \\
\hline 3 & Asp173 & -1 & ${ }_{a}^{a} c_{\beta}^{\prime \prime}$ & ${ }_{a}^{a} c_{\beta}$ & ${ }_{a}^{a} c_{\beta}^{\prime \prime}$ & ${ }_{a}^{\prime} c^{\prime \prime}$ & ${ }_{a}^{a} c_{\beta}^{\prime \prime}$ & ${ }_{a}{ }_{a}^{\prime \prime}$ \\
\hline 4 & Ser174 & 0 & & $\begin{array}{cc}a 1 & c \\
a & \beta\end{array}$ & & $a$ & $\begin{array}{cc}a & c \\
a & \beta\end{array}$ & ${ }_{a}{ }_{a}{ }^{\prime} \beta$ \\
\hline 5 & Gln175 & 0 & $a c$ & ${ }_{a}^{a} c^{1}$ & ${ }_{a}^{\prime}{ }^{\prime \prime} \beta$ & ${ }_{a}^{a}{ }_{\beta} \beta$ & ${ }_{a}^{a} c^{\prime \prime}$ & ${ }_{a}{ }_{a}{ }^{\prime}$ \\
\hline 6 & Glu212 & -1 & ${ }_{a}^{a} c^{\prime \prime} \beta$ & ${ }_{a}^{\prime \prime} c^{\prime \prime}$ & $a$ & $\begin{array}{ll}a c & c\end{array}$ & ${ }_{a}^{\prime \prime}{ }^{\prime \prime} \beta$ & ${ }_{a}^{a}{ }_{\beta}$ \\
\hline 7 & Asp214 & 0 & ${ }^{\prime \prime} a{ }^{\prime \prime} \beta$ & ${ }_{a}^{a} c^{\prime \prime}$ & $a{ }_{a}^{\prime} \beta$ & $a$ & ${ }_{a}^{a}{ }^{\prime \prime} \beta$ & ${ }_{a}{ }_{a}^{\prime \prime}$ \\
\hline 8 & Glu/Gln217 & $0 /+1$ & $a{ }_{a}^{\prime \prime} \beta$ & ${ }_{a}^{\prime \prime}{ }^{\prime \prime} \beta$ & $a c$ & $a$ & ${ }_{a}^{\prime \prime}{ }^{\prime \prime} \beta$ & ${ }_{a}^{\prime \prime} \beta$ \\
\hline 9 & Thr226 & 0 & & 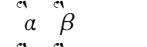 & & $\begin{array}{lll}a 1 & c\end{array}$ & $\begin{array}{lll}a & c & \beta\end{array}$ & ${ }_{a}^{a}{ }_{a}^{\prime \prime}$ \\
\hline 10 & His 228 & +1 & ${ }_{a}^{a}{ }^{\prime \prime} \beta$ & ${ }_{a}^{a} c_{\beta}^{\prime \prime}$ & ${ }_{a}^{\prime \prime}{ }^{\prime \prime} \beta$ & ${ }^{\prime \prime} a c^{\prime \prime} \beta$ & ${ }^{\prime \prime} a{ }_{a}^{\prime \prime} \beta$ & ${ }^{\prime \prime} a{ }^{\prime \prime} \beta$ \\
\hline 11 & Thr246 & 0 & & ${ }_{a}^{a}{ }^{\prime \prime} \beta$ & & & & ${ }_{a}^{a}{ }_{a}^{\prime \prime} \beta$ \\
\hline 12 & $\operatorname{Arg} 251$ & +1 & ${ }_{a}^{a} c_{\beta}^{\prime \prime}$ & ${ }_{a}^{a} c^{\prime \prime}$ & ${ }_{a}^{\prime \prime} c_{\beta}^{\prime \prime}$ & & ${ }_{a}^{a} c^{\prime \prime}$ & ${ }_{a}^{\prime \prime}{ }^{\prime \prime} \beta$ \\
\hline & Asp257 & -1 & & ${ }_{a}^{a}$ & & ${ }^{\prime \prime}$ & ${ }^{\prime \prime}$ & ${ }_{a}^{a}$ \\
\hline 13 & Pro258 & 0 & & $\stackrel{a}{a}$ & & ${ }^{\prime \prime}$ & ${ }^{a}$ & ${ }_{a}^{a}$ \\
\hline 14 & Asp259 & 0 & ${ }_{a}^{\prime}$ & $\stackrel{c}{a}$ & ${ }^{a}$ & ${ }^{\prime \prime}$ & ${ }^{a}$ & ${ }_{a}^{a}$ \\
\hline & Gly260 & 0 & ${ }^{a} a$ & ${ }^{\prime \prime} a$ & ${ }^{\prime \prime} a$ & ${ }^{\prime \prime} a$ & ${ }^{\prime \prime} a$ & ${ }^{a} a$ \\
\hline 15 & Trp367 & 0 & ${ }^{\prime \prime} a c^{\prime \prime} \beta$ & ${ }^{a} a{ }_{a}^{\prime \prime} \beta$ & ${ }^{a} a{ }^{\prime \prime} \beta$ & ${ }^{a} a{ }^{\prime \prime} \beta$ & ${ }^{a} a{ }^{\prime \prime} \beta$ & ${ }^{\prime \prime} a{ }^{\prime \prime} \beta$ \\
\hline 16 & Trp376 & 0 & $a_{a}^{\prime \prime} \quad \beta$ & $a_{a}^{a c} \beta$ & ${ }^{a} a{ }^{\circ} \beta$ & $a_{a}^{\prime \prime} \quad \beta$ & ${ }^{a} a{ }^{\prime \prime} \beta$ & ${ }_{a}^{a} c^{\prime \prime} \beta$ \\
\hline 17 & Glc +1 & 0 & $\mathrm{X}$ & $\mathrm{X}$ & $\mathrm{X}$ & $\mathrm{X}$ & $\mathrm{X}$ & $\mathrm{X}$ \\
\hline 18 & Glc-1 & 0 & $\mathrm{X}$ & $\mathrm{X}$ & $\mathrm{X}$ & $\mathrm{X}$ & $\mathrm{X}$ & $\mathrm{X}$ \\
\hline 19 & HOH1 & 0 & $\mathrm{X}$ & $\mathrm{X}$ & $\mathrm{X}$ & $\mathrm{X}$ & $\mathrm{X}$ & $\mathrm{X}$ \\
\hline 20 & $\mathrm{HOH} 2$ & 0 & $\mathrm{X}$ & $\mathrm{X}$ & $\mathrm{X}$ & $\mathrm{X}$ & $\mathrm{X}$ & $\mathrm{X}$ \\
\hline 21 & НOH3 & 0 & & $\mathrm{X}$ & & $\mathrm{X}$ & $\mathrm{X}$ & $\mathrm{X}$ \\
\hline 22 & HOH4 & 0 & & & & $\mathrm{X}$ & $\mathrm{X}$ & $\mathrm{X}$ \\
\hline 23 & HOH5 & 0 & & & & & & $\mathrm{X}$ \\
\hline
\end{tabular}




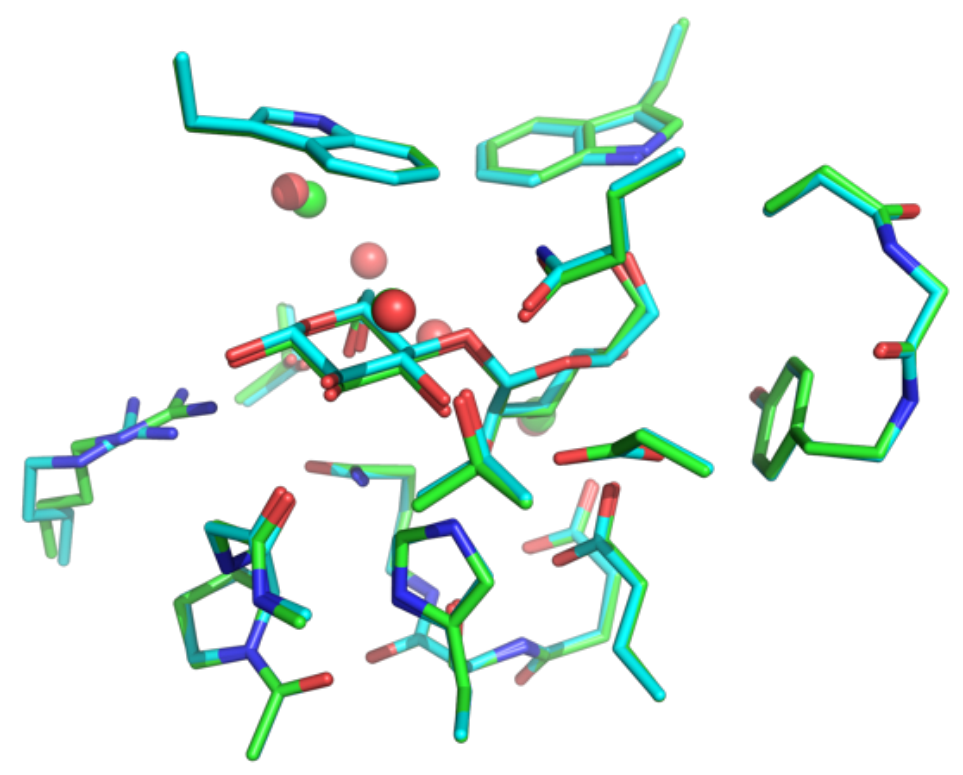

Figure 1: Aligned 21-residue model of 8CEL Res21-E(green, waters in green sphere) and 23- residue model of 4C4CRes23-Q (cyan, waters in red sphere).

\section{Hosted file}

image2.emf available at https://authorea.com/users/451004/articles/549260-a-case-study-ofthe-glycoside-hydrolase-enzyme-mechanism-using-an-automated-qm-cluster-model-buildingtoolkit

\section{Hosted file}

image3.emf available at https://authorea.com/users/451004/articles/549260-a-case-study-ofthe-glycoside-hydrolase-enzyme-mechanism-using-an-automated-qm-cluster-model-buildingtoolkit

\section{Hosted file}

image4.emf available at https://authorea.com/users/451004/articles/549260-a-case-study-ofthe-glycoside-hydrolase-enzyme-mechanism-using-an-automated-qm-cluster-model-buildingtoolkit

\section{Hosted file}

image5.emf available at https://authorea.com/users/451004/articles/549260-a-case-study-ofthe-glycoside-hydrolase-enzyme-mechanism-using-an-automated-qm-cluster-model-buildingtoolkit

Figure 2: (a) 2D structure of the Res21-E (8CEL) model. The wavy lines indicate truncation of the residue at ${ }_{a}^{\text {c }}$. (b) $2 \mathrm{D}$ structure of the $\operatorname{Res} 23-\mathbf{Q}(4 \mathrm{C} 4 \mathrm{C})$ model. The wavy lines indicate truncation of the residue at ${ }_{a}^{\text {" }}$. Atom labeling scheme of +1 and -1 glucosyl units (c) in 8 CEL and (d) in 4 C4C. 


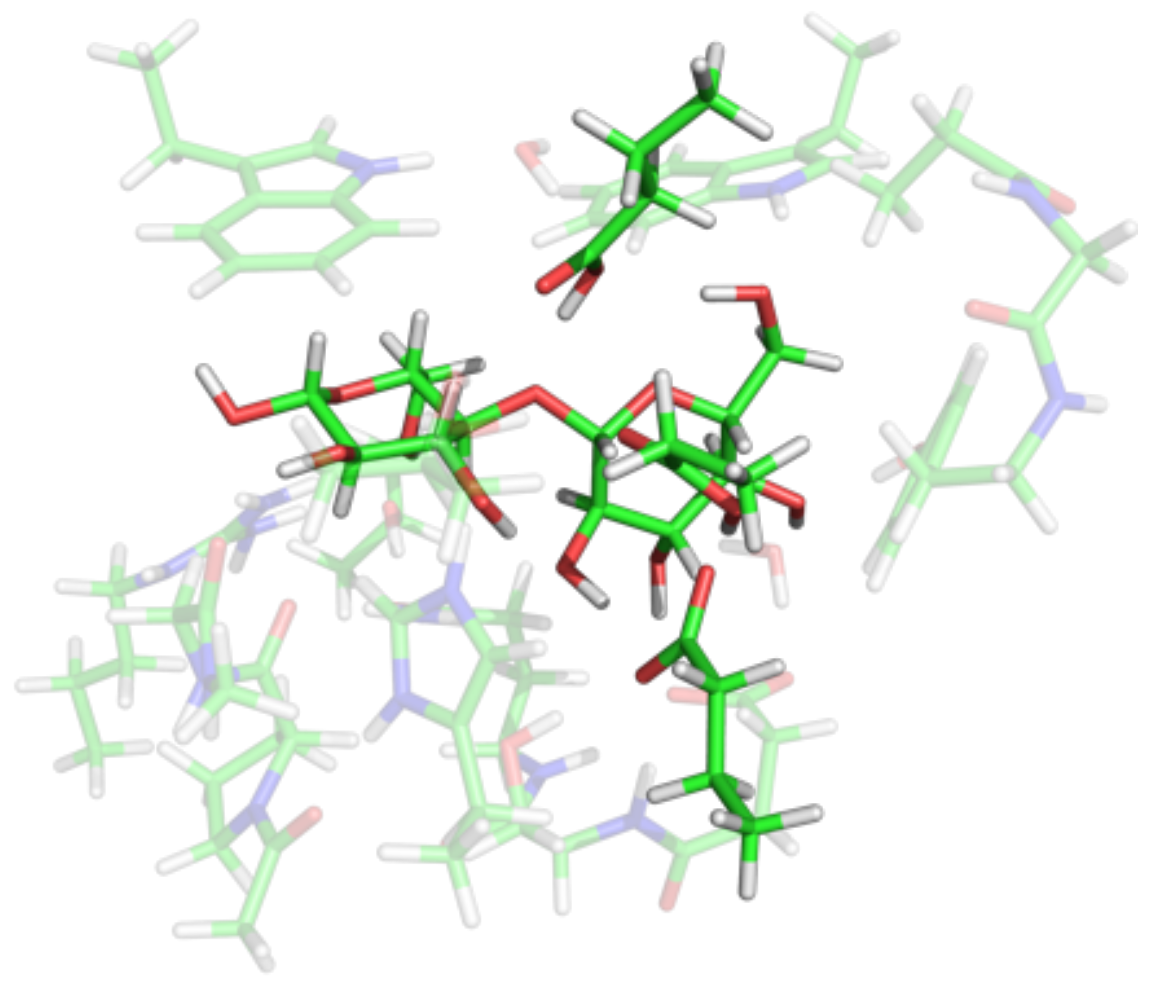




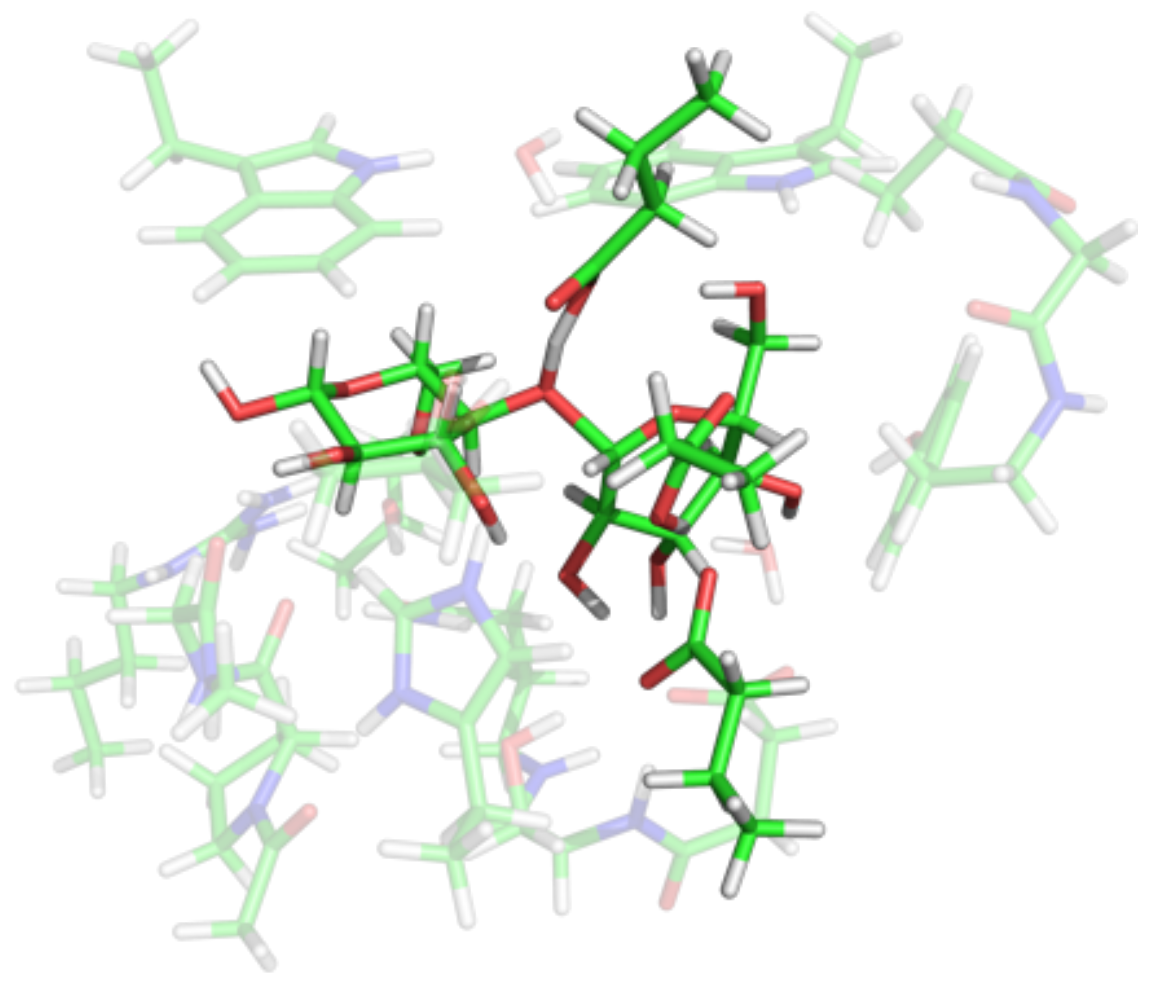




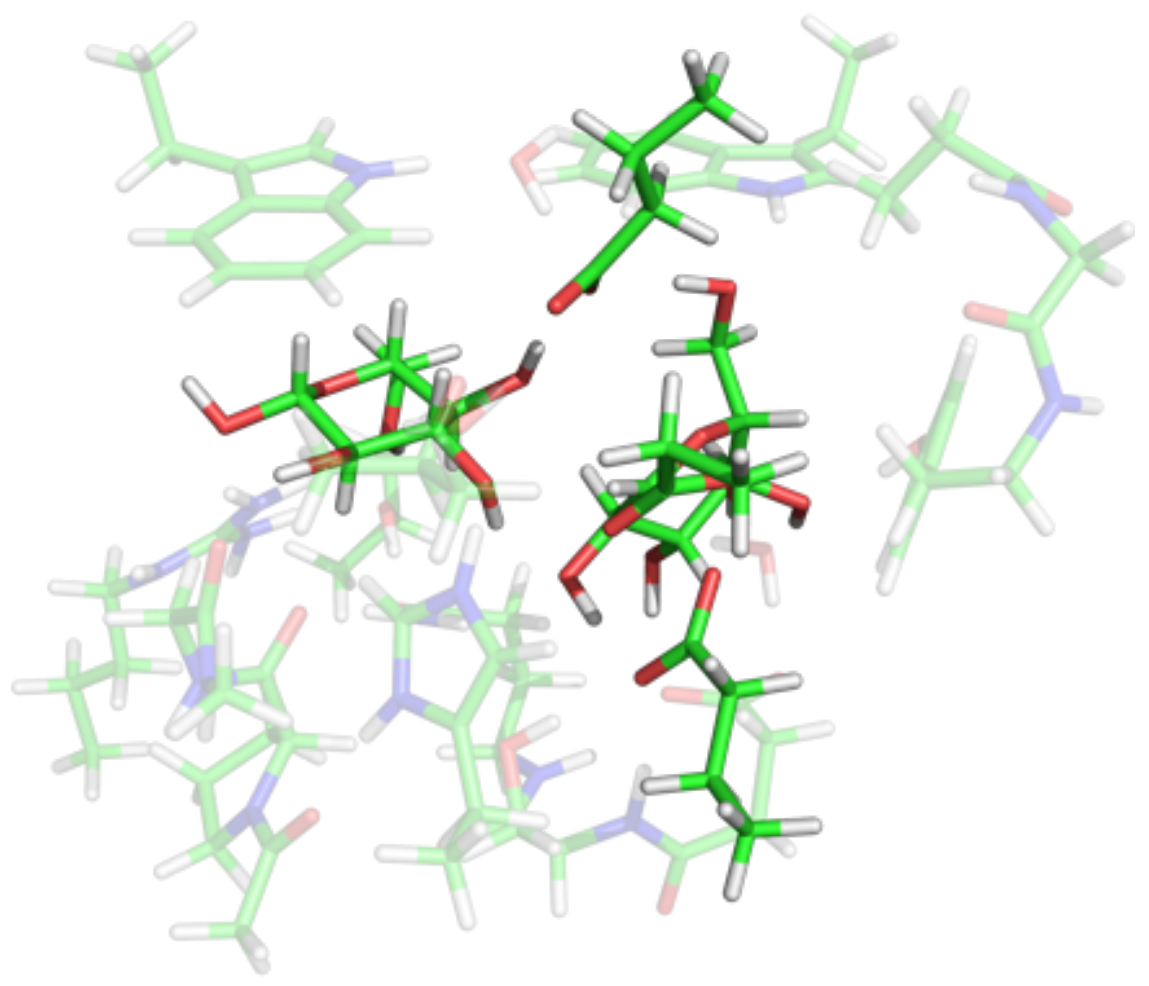

Figure 3 : Glycosylation of the Res21-E model of 8CEL. 


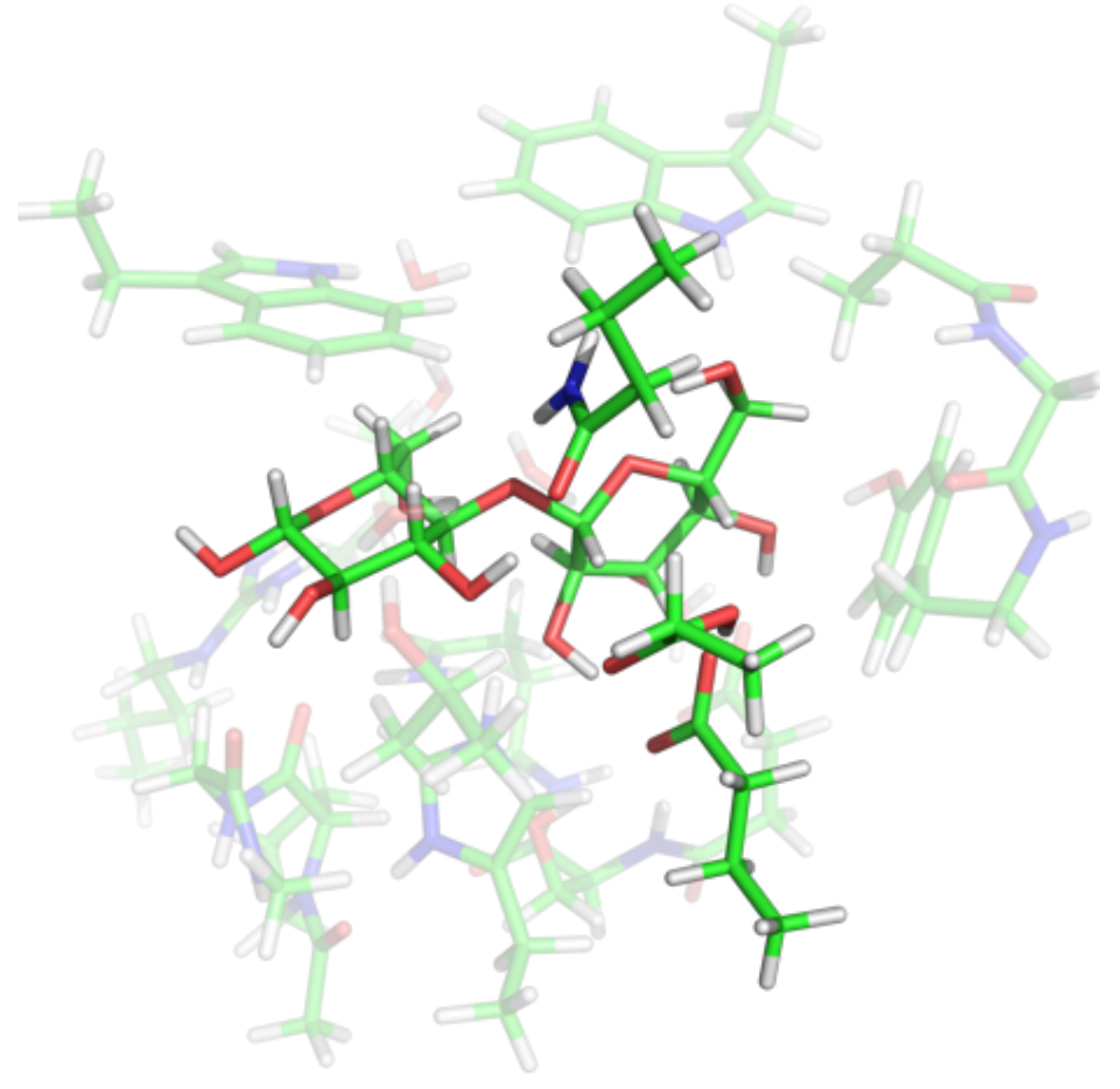




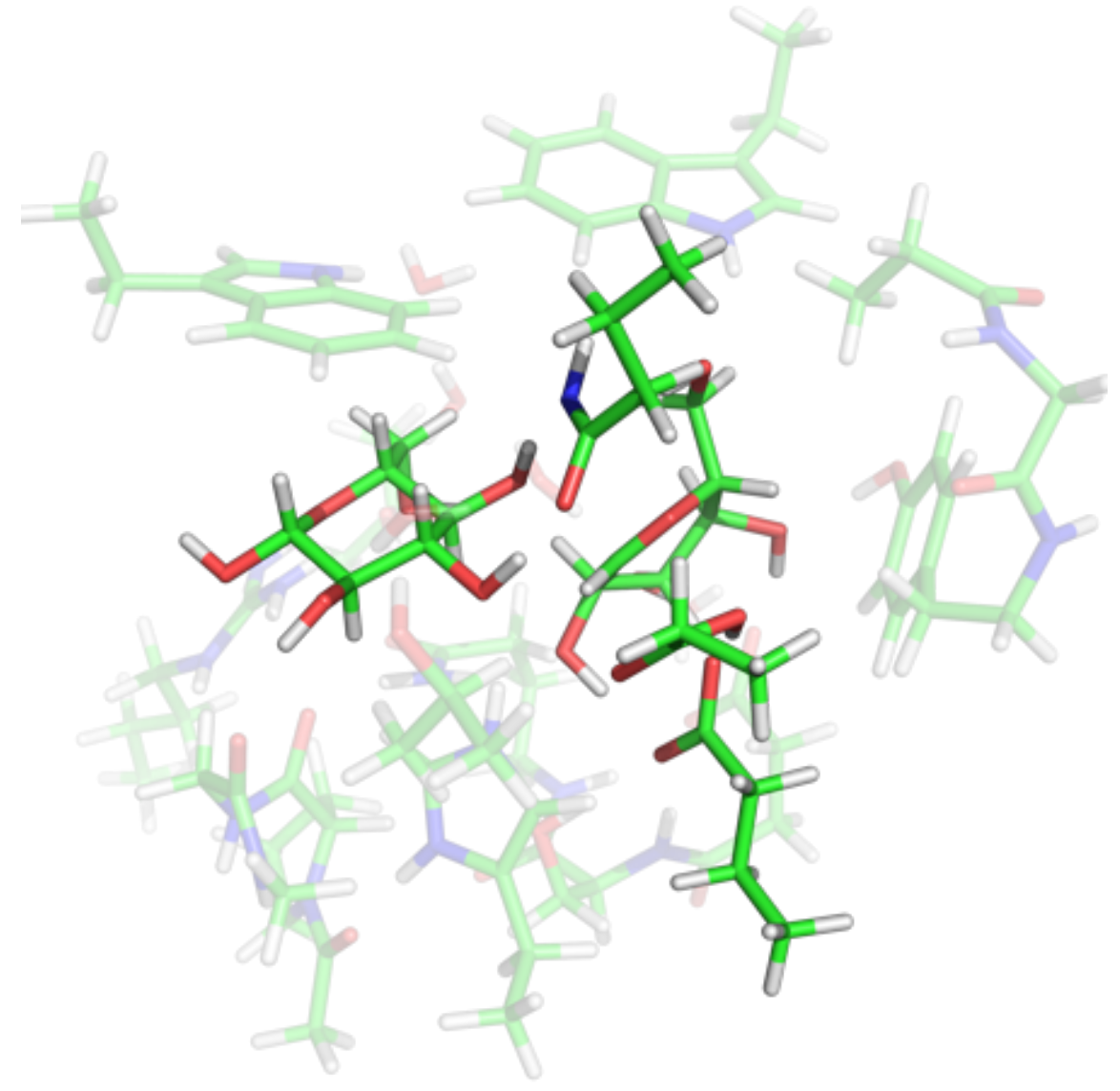




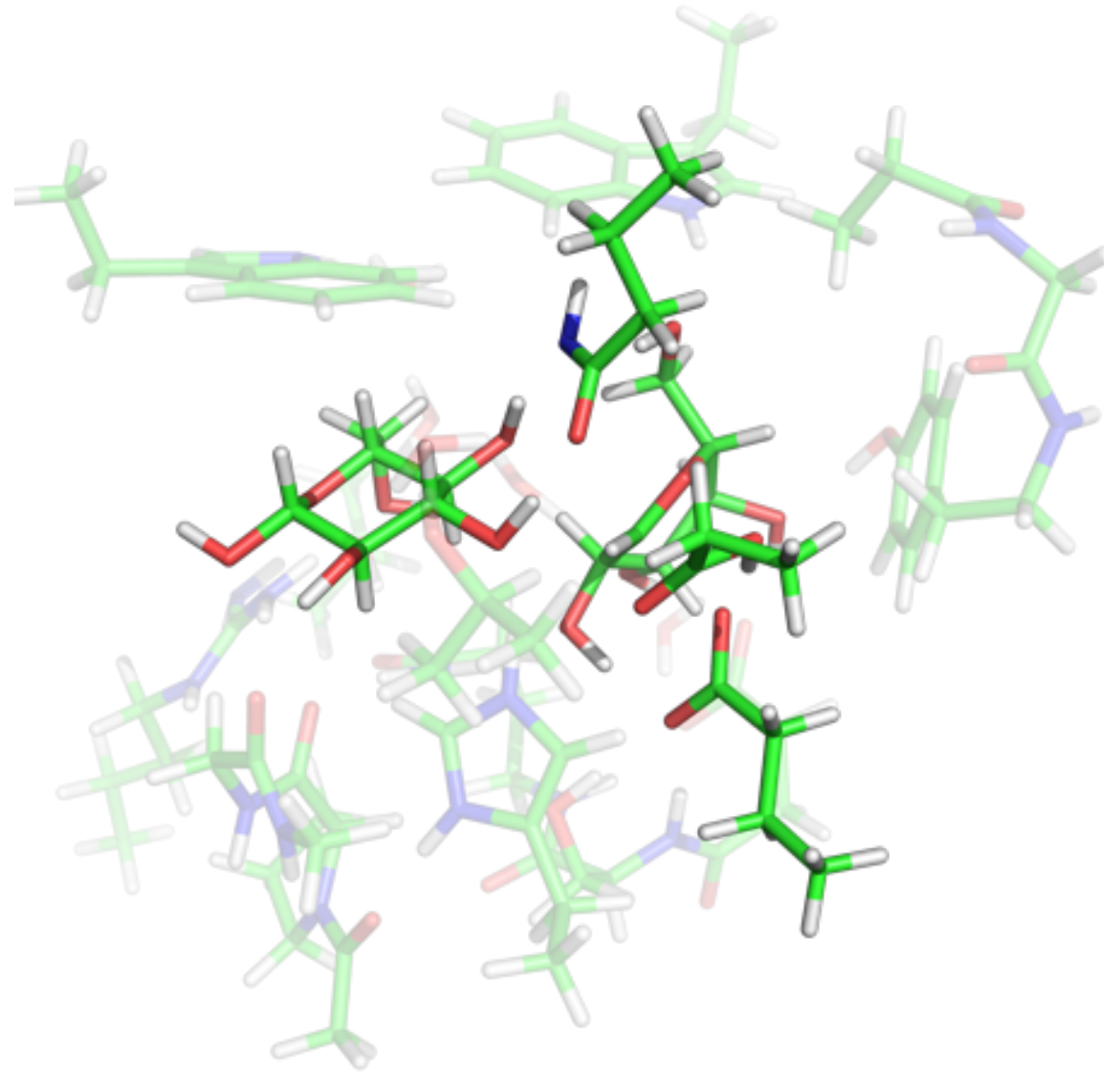

Figure 4 : Glycosylation of the Res23-Q model of 4C4C. 


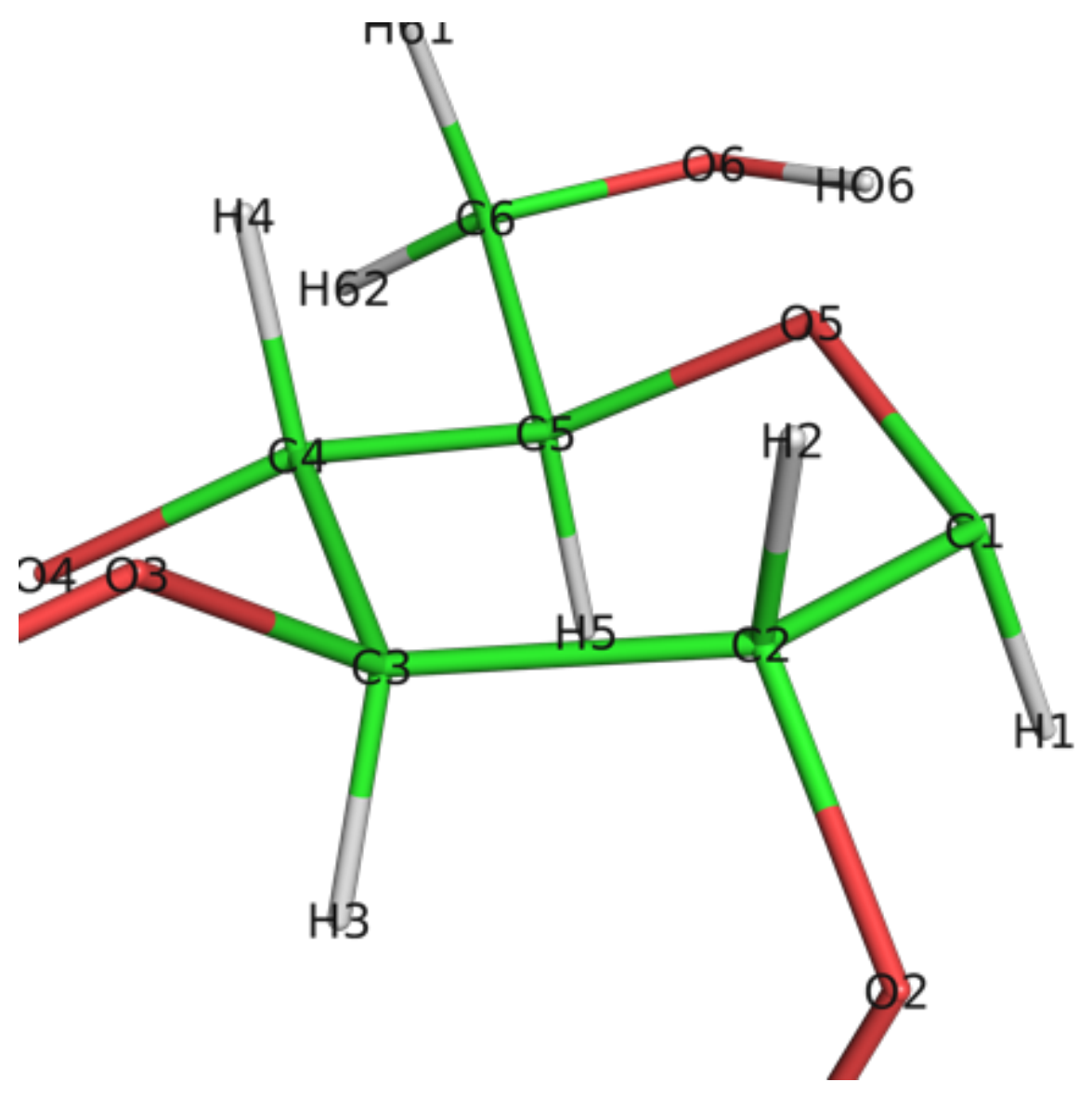




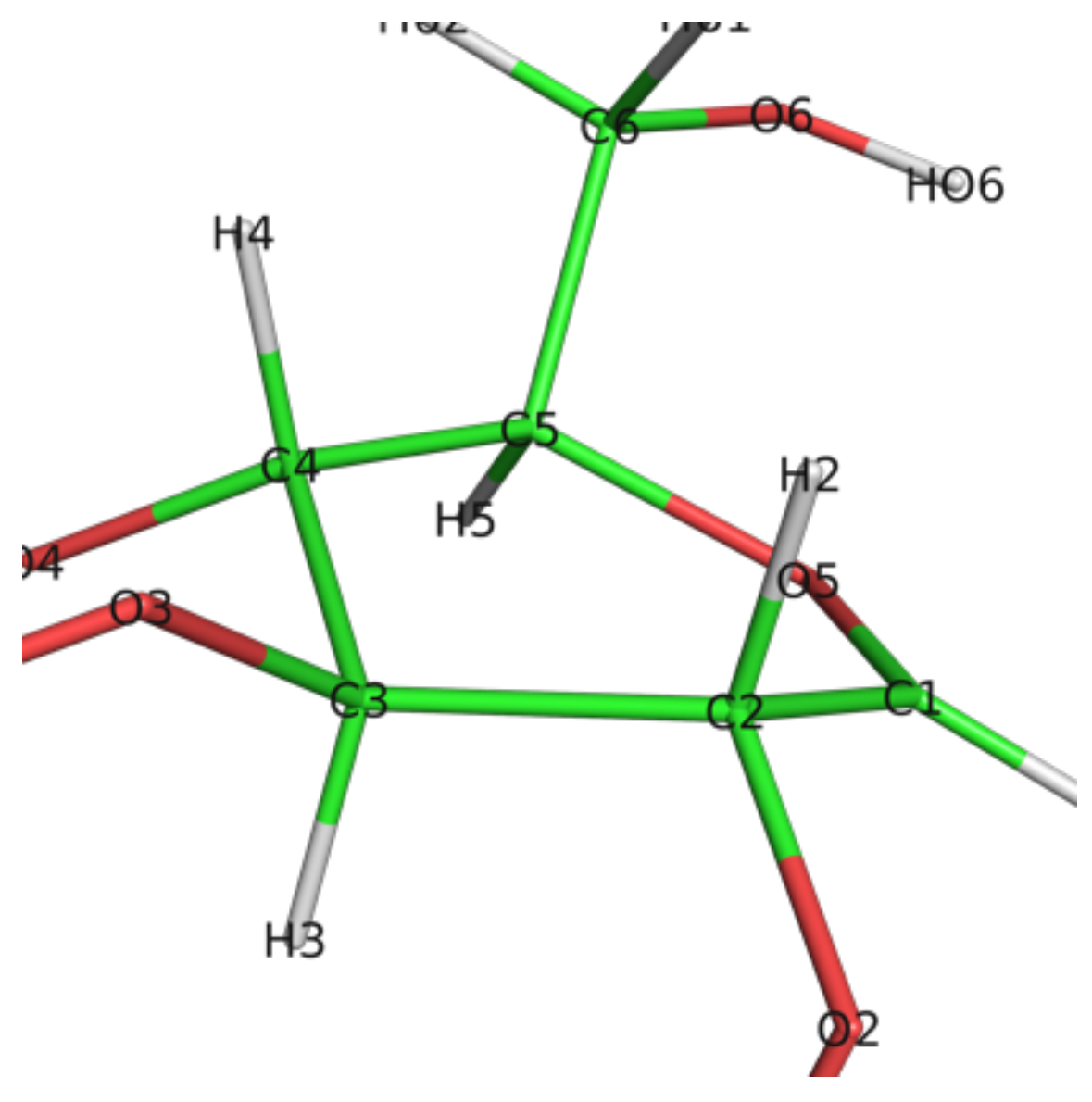




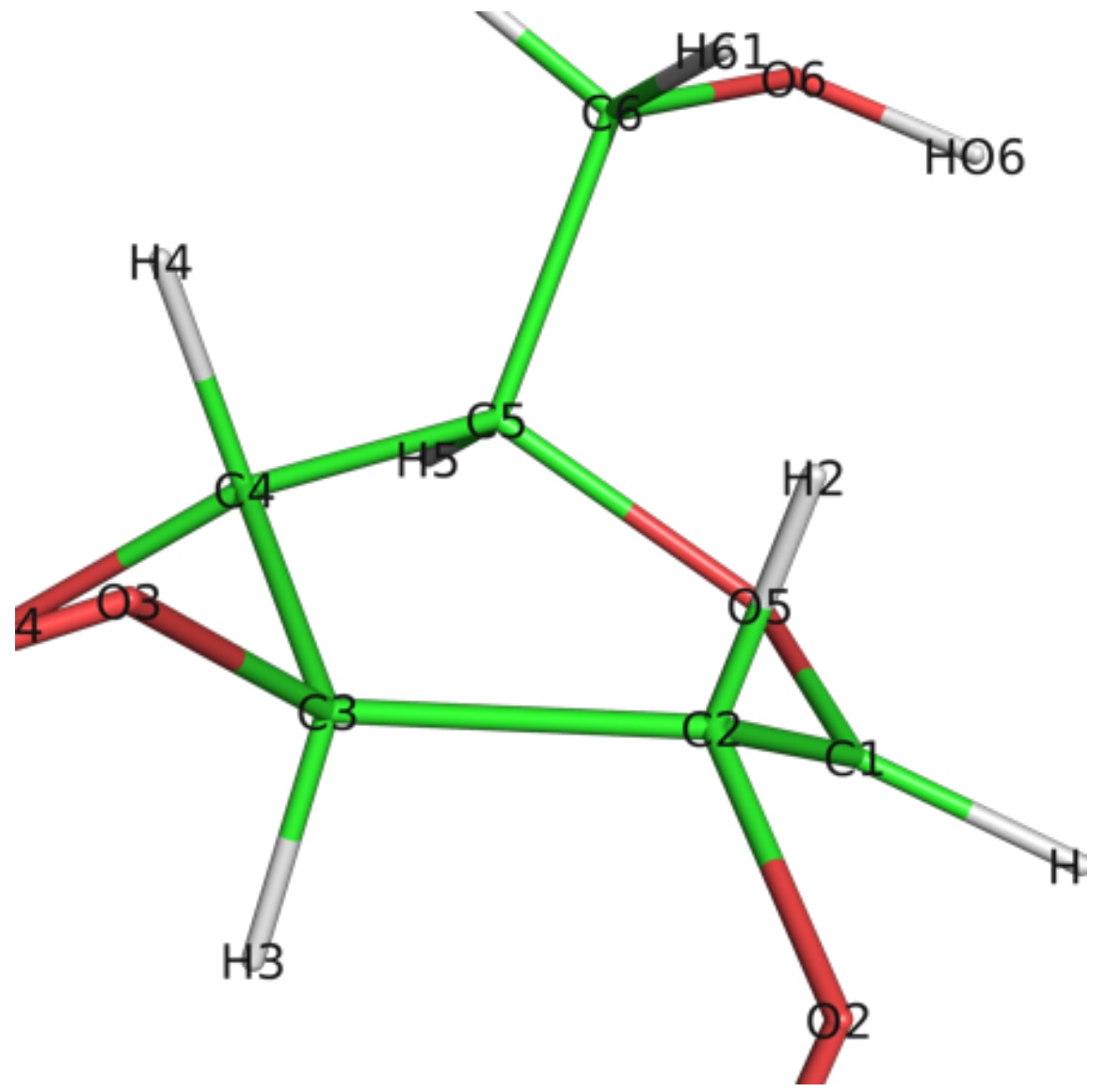

Figure 5: Conformational change of the glycosyl unit Glc-1 in the glycosylation reaction from ${ }^{4} \mathrm{E}^{4}{ }^{4} \mathrm{H}_{3}$ to ${ }^{4} \mathrm{C}_{1}$. 


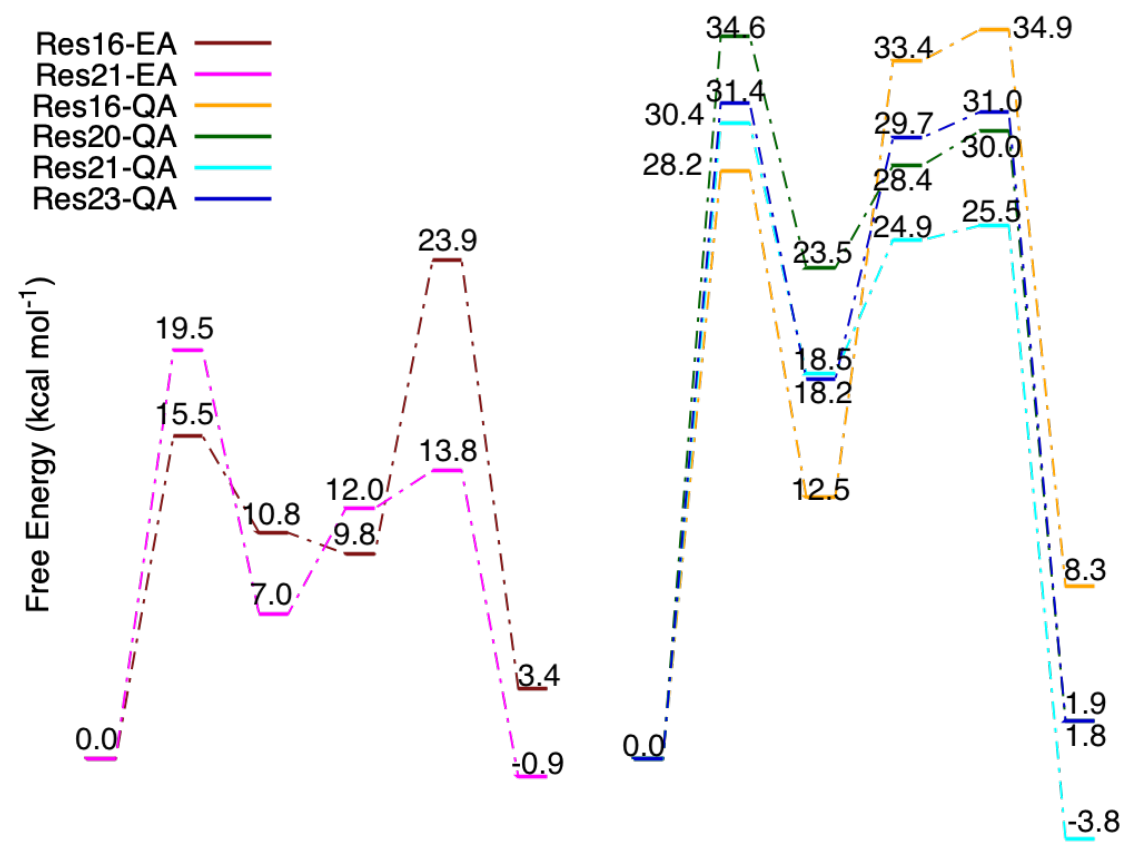

Figure 6 : Free energy diagram of the glycosylation and deglycosylation for models Res16-E (brown) and Res21-E(magenta) which are built using PDB 8CEL (E217, wild-type protein) andRes16-Q (orange), Res20-Q (green), Res21-Q(cyan), and Res23-Q (blue) which are built using PD 


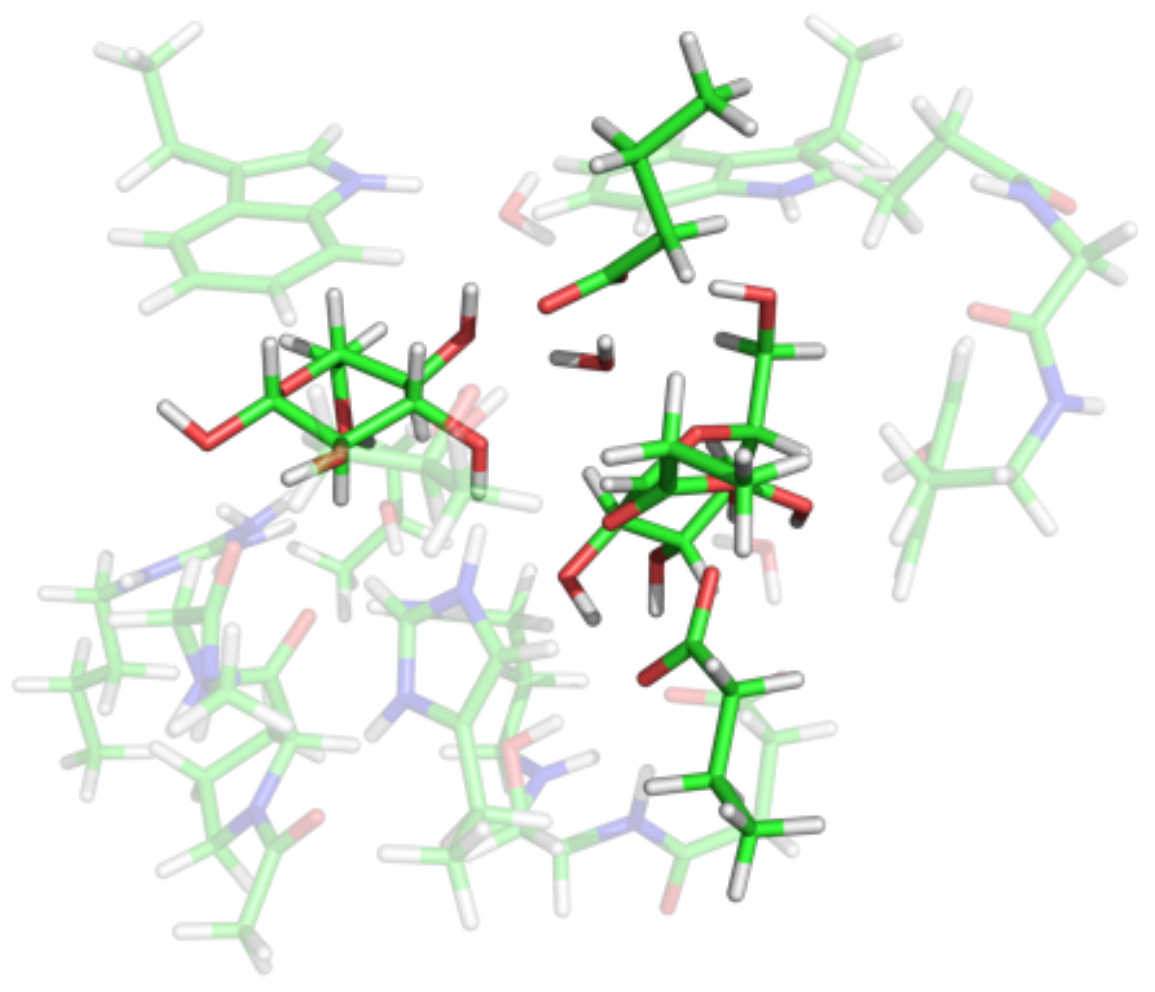




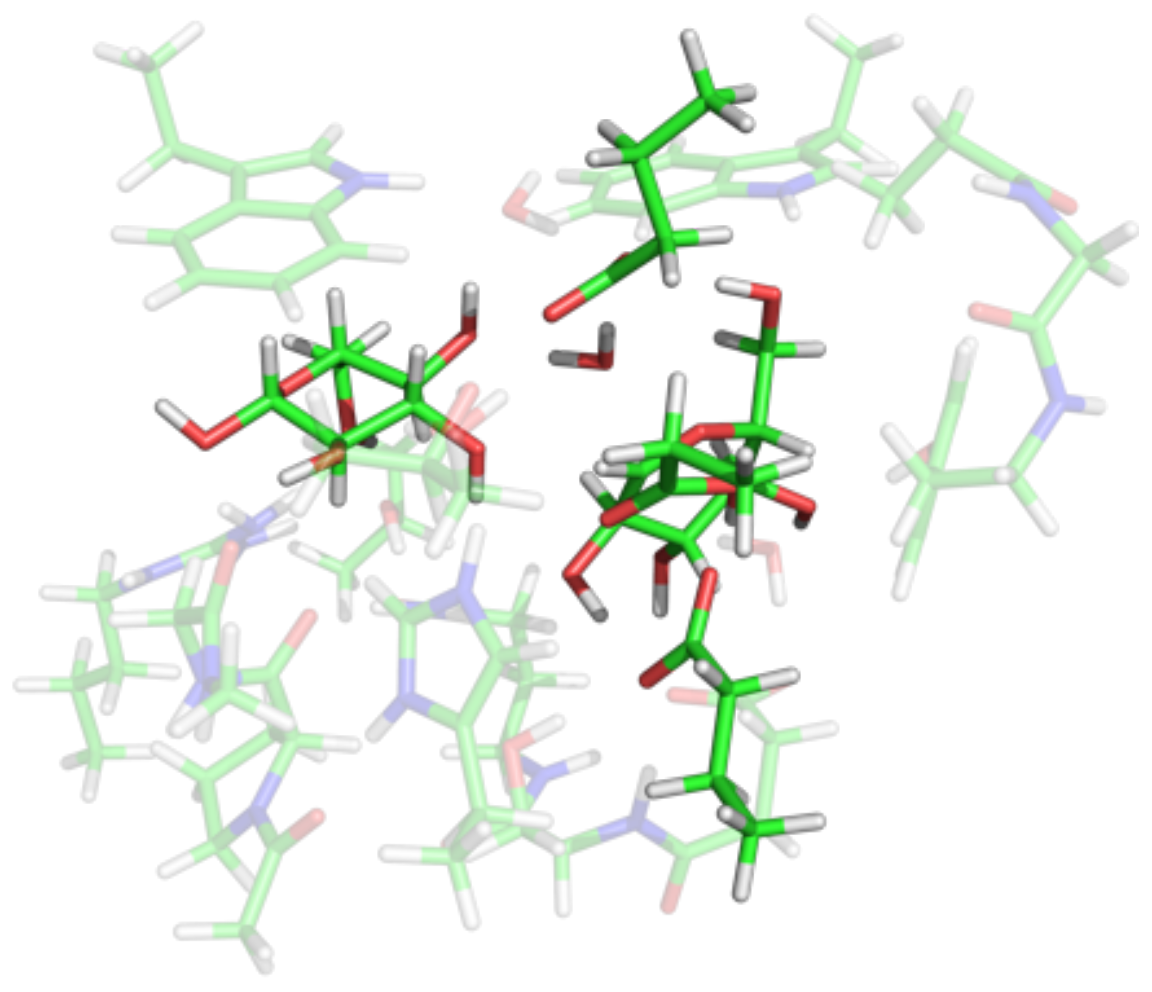




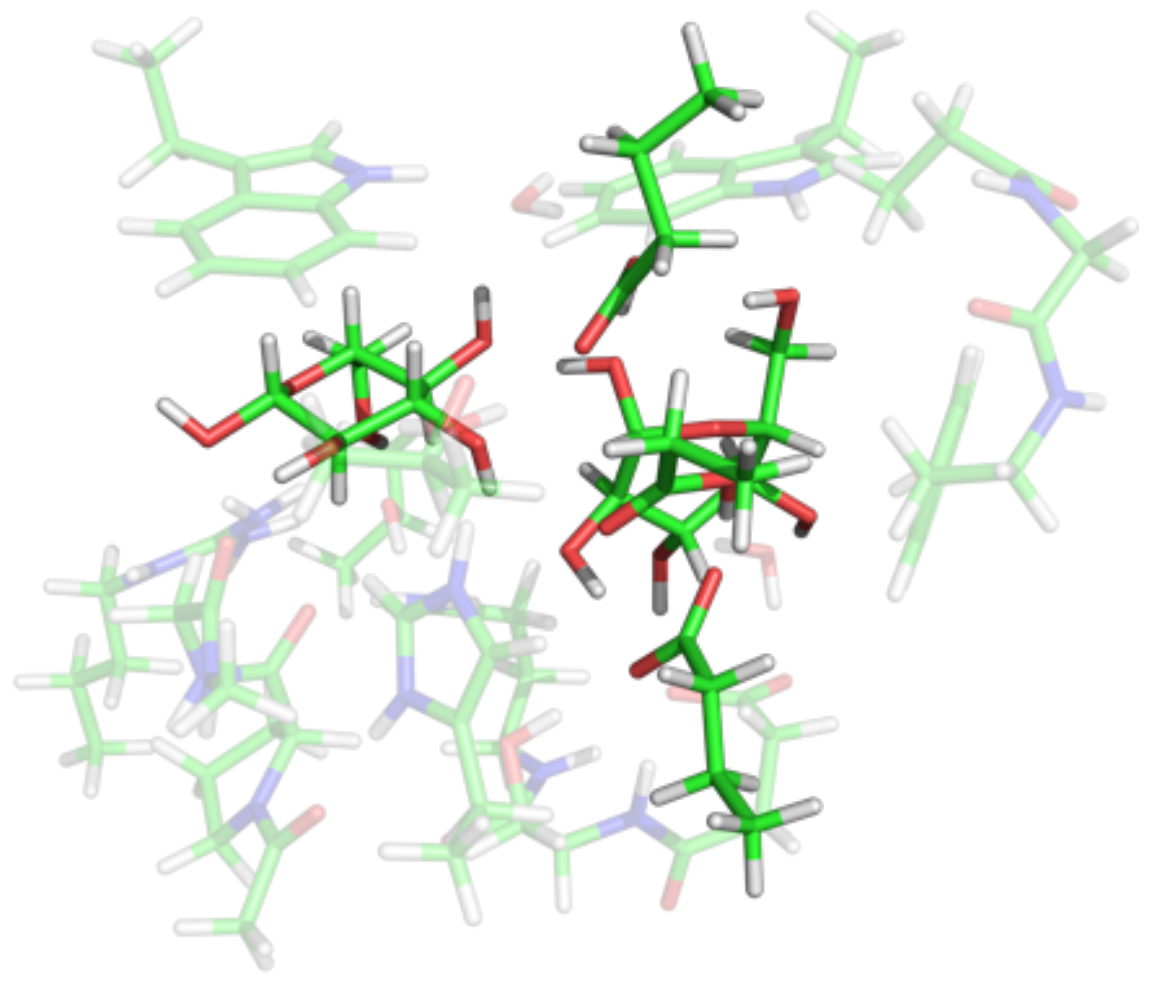

Figure 7 : Deglycosylation of the Res21-E model of 8CEL. 


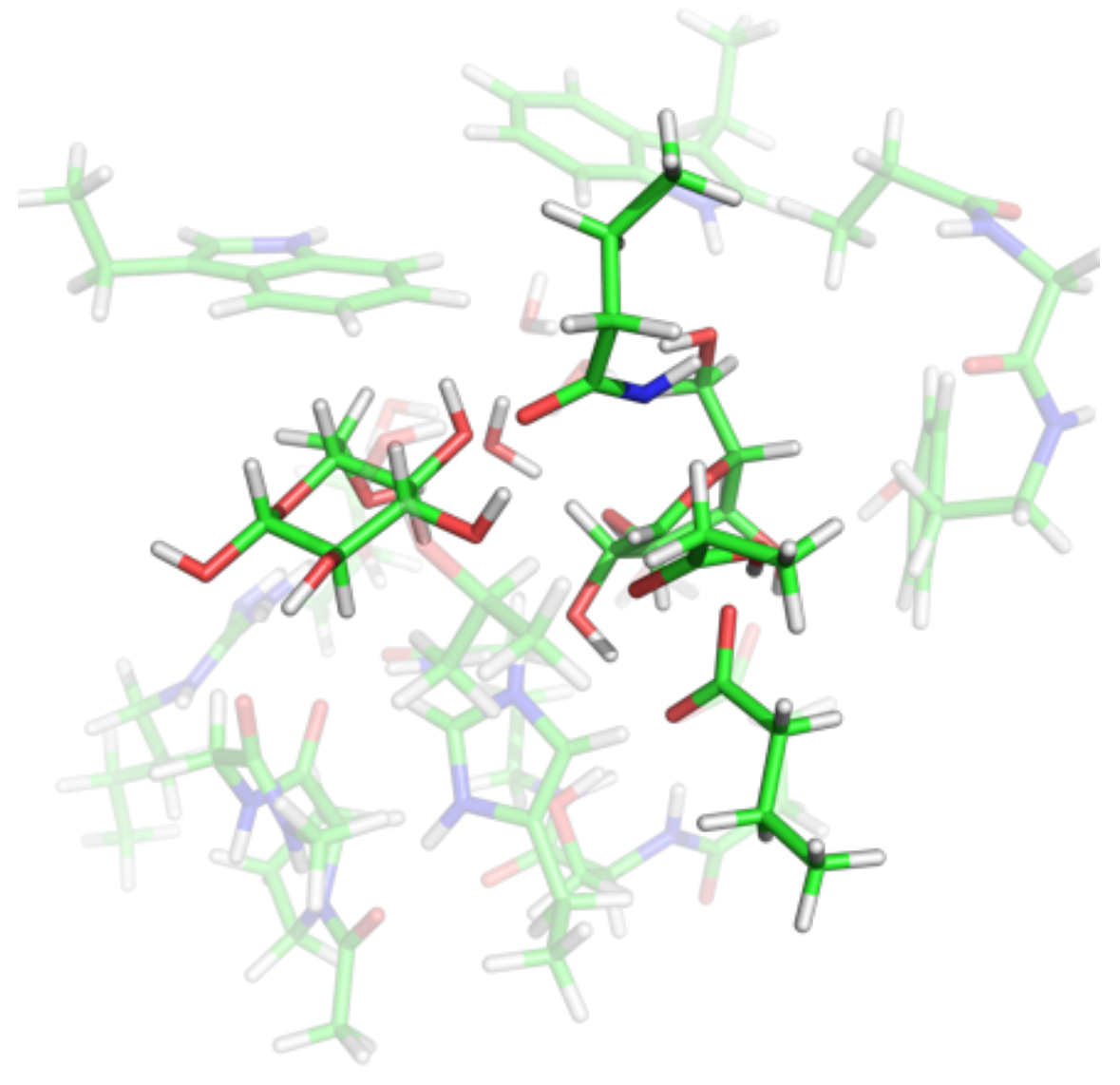




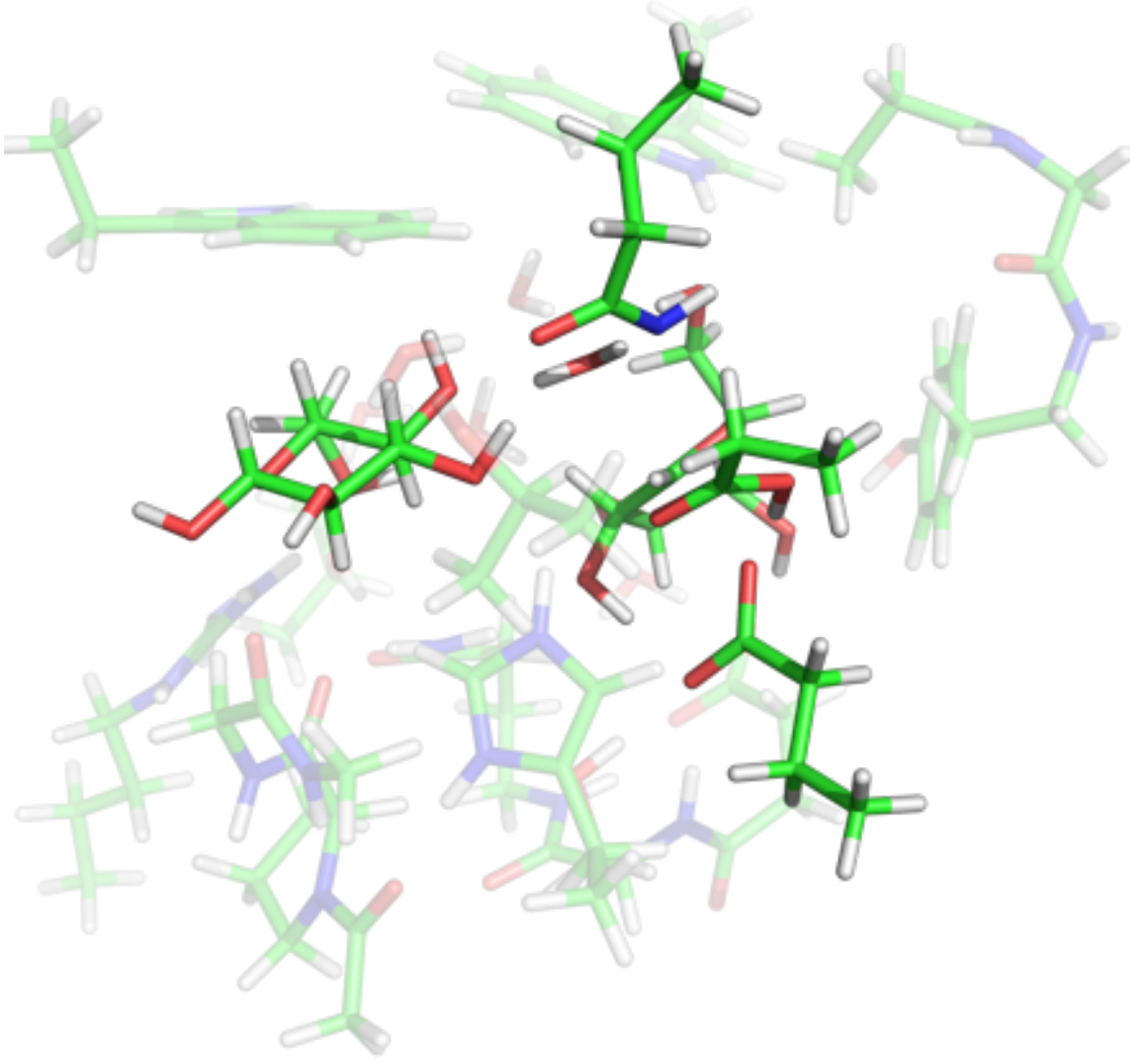




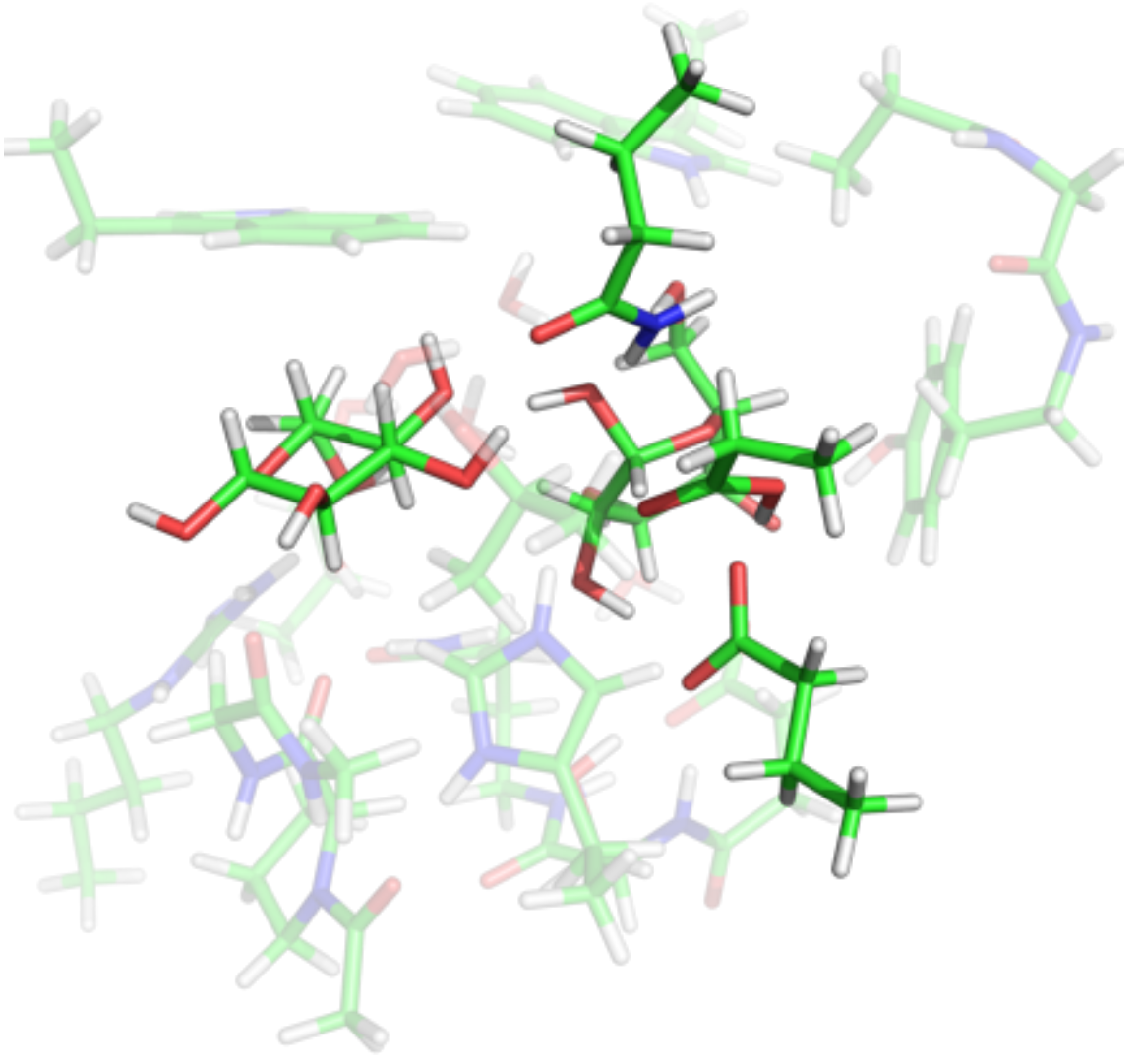

Figure 8 : Deglycosylation of the Res23-Q model of 4C4C. 


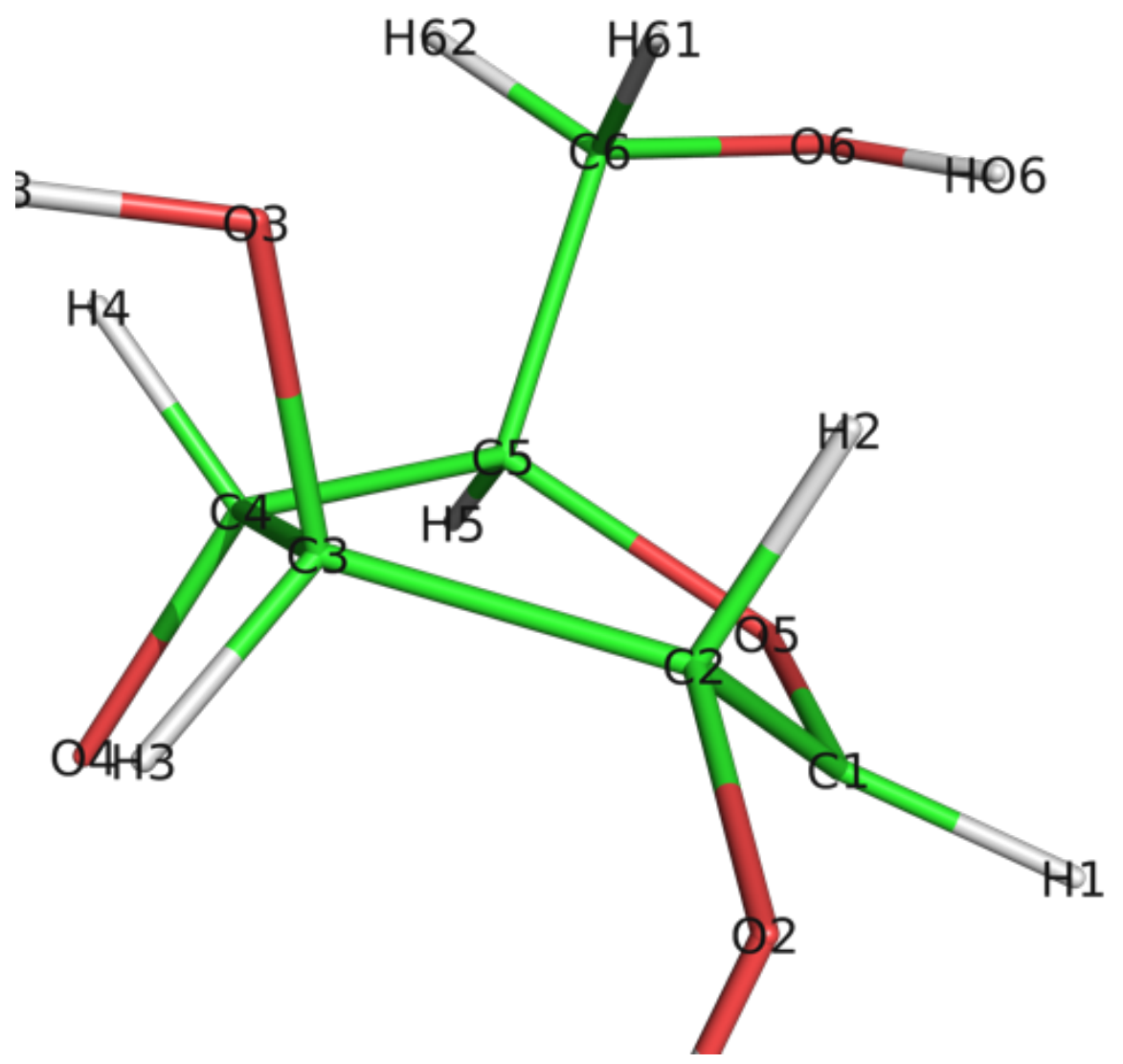




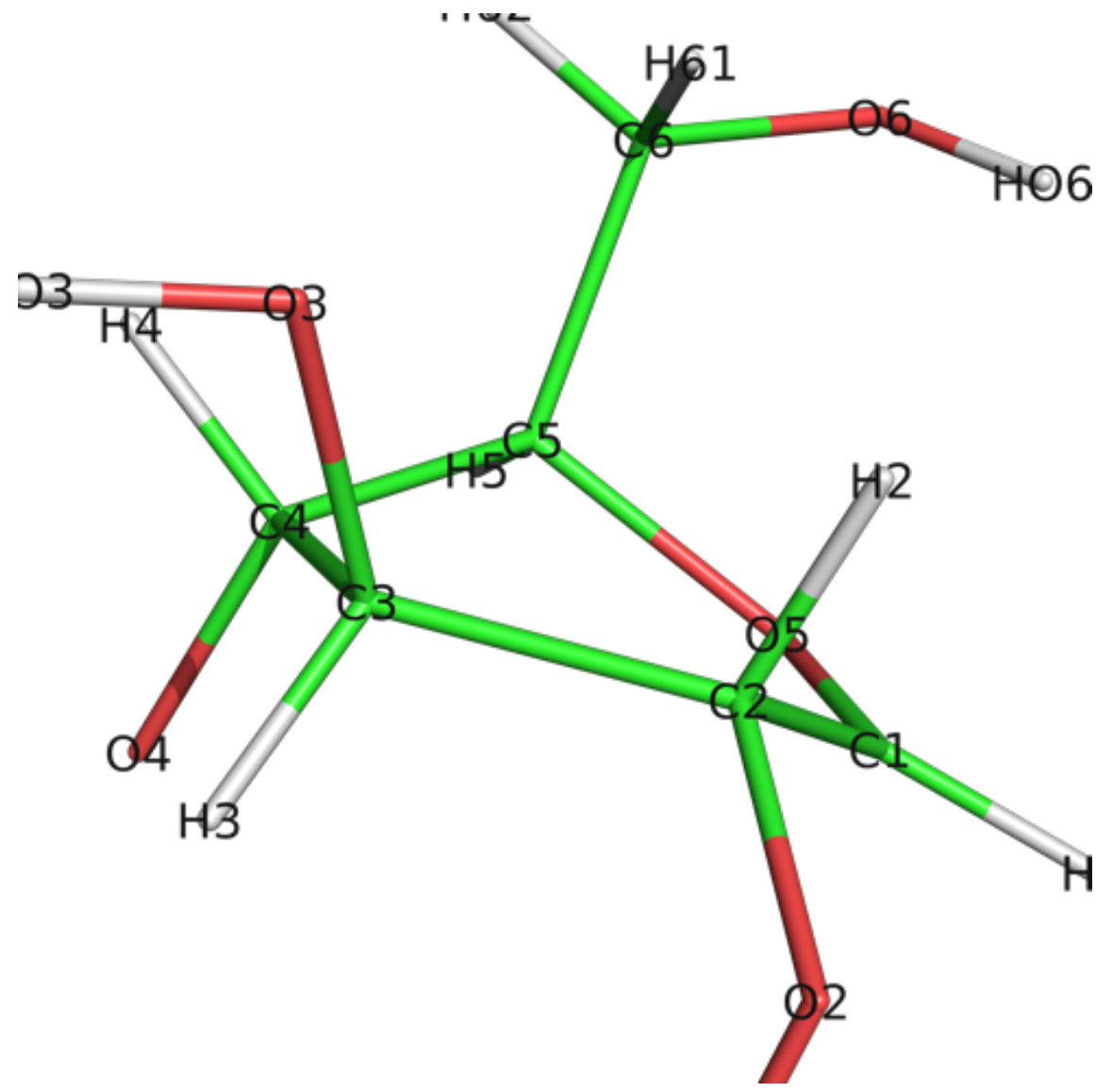




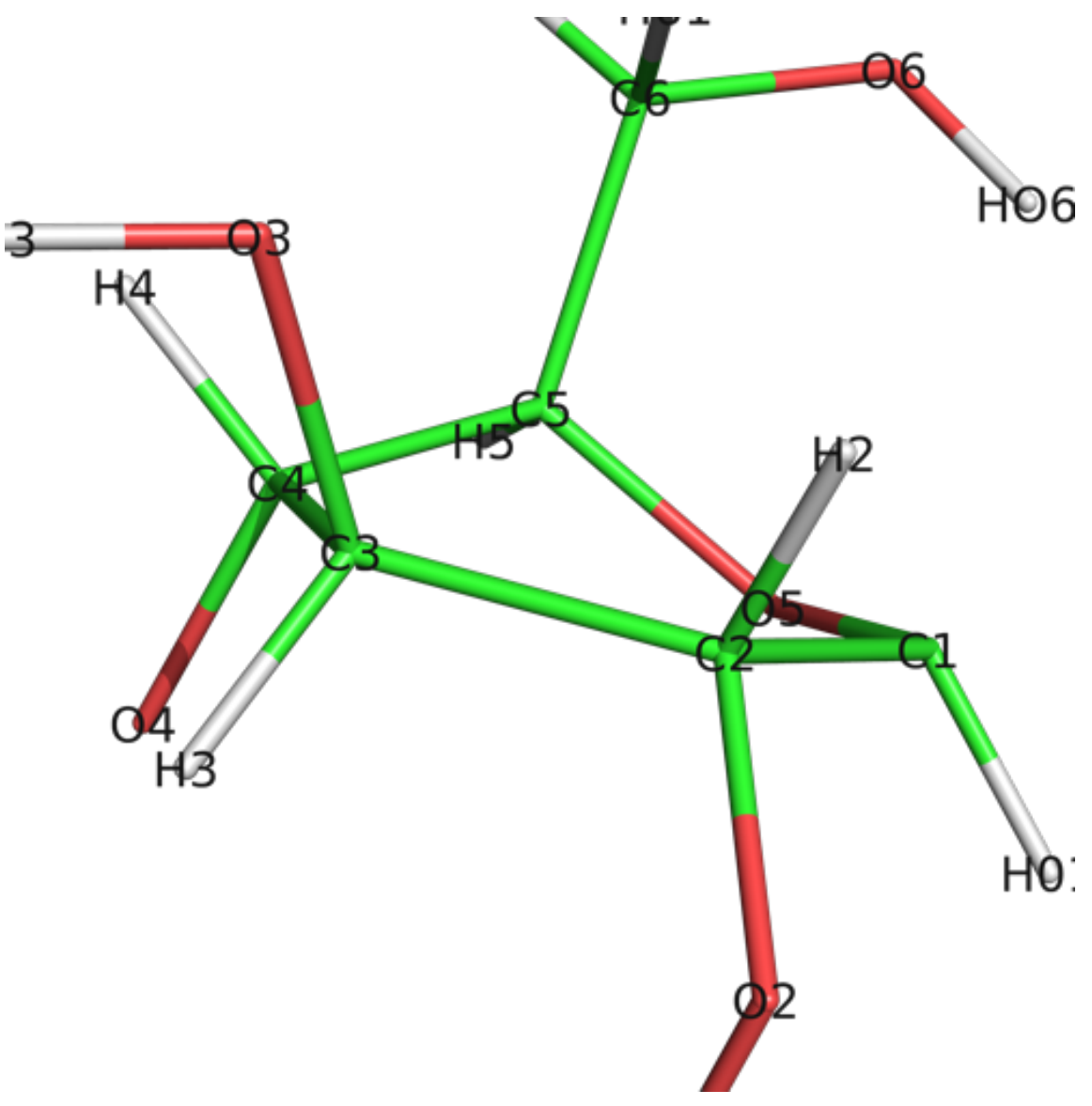

Figure 9: Conformational change of the glycosyl unit Glc-1 in the deglycosylation reaction from ${ }^{4} \mathrm{C}_{1}$ to ${ }^{4} \mathrm{H}_{3}$ to ${ }^{4} \mathrm{E}$. 


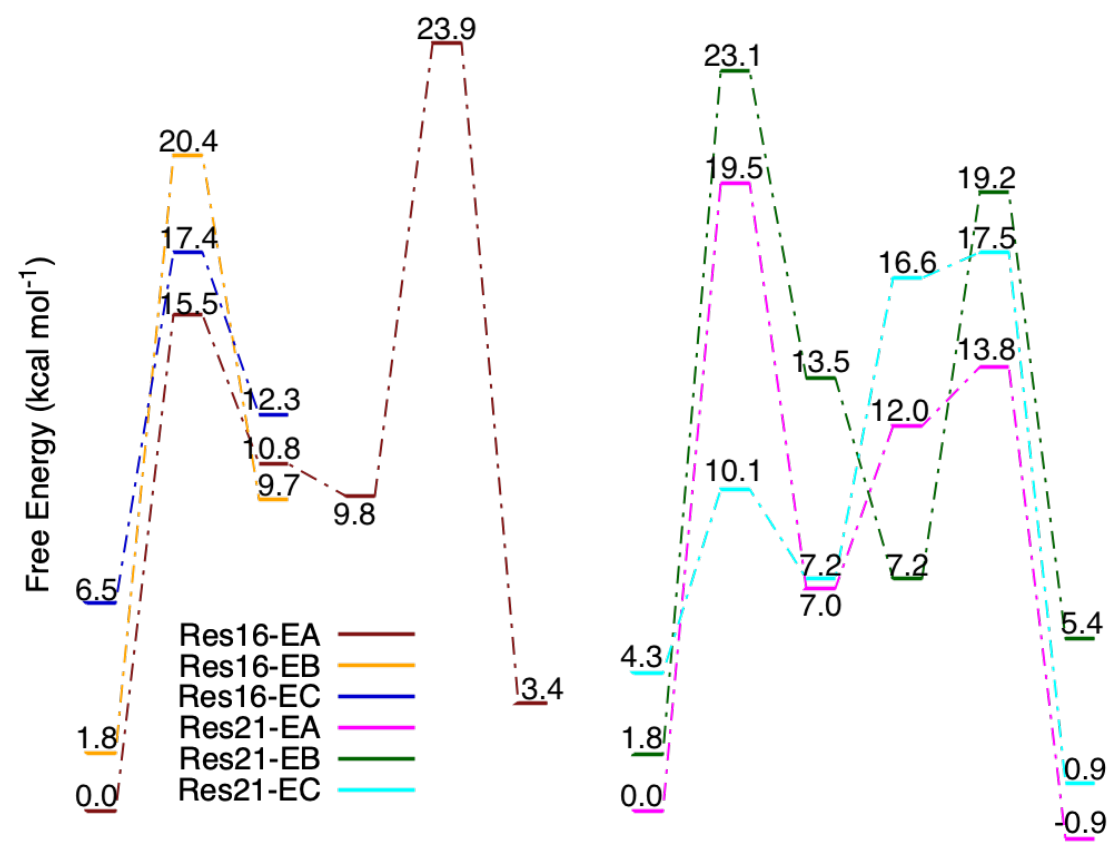

Figure 10 : Free energy diagram of glycosylation for different conformers with models Res16-E and Res21-E based on 8CEL.

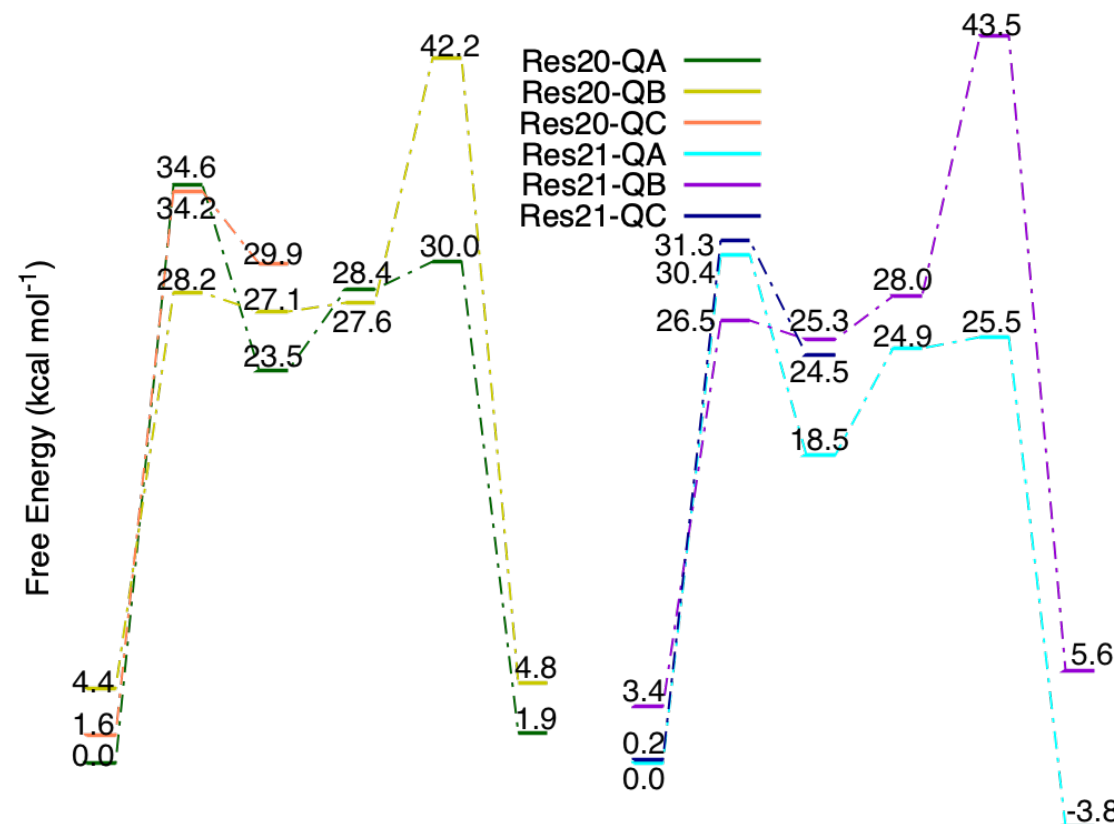

Figure 11 : Free energy diagram of glycosylation and deglycosylation for different conformers with models Res20-Qand Res21-Q based on 4C4C. 


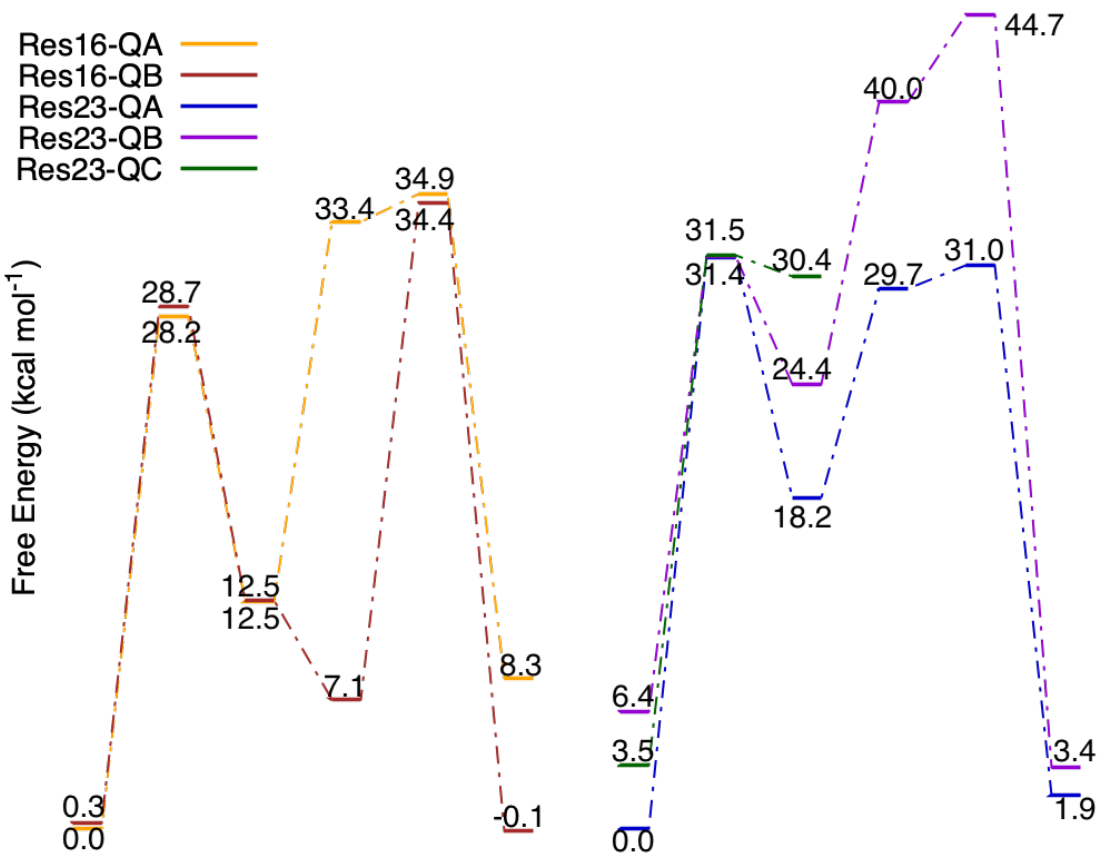

Figure 12: Free energy diagram of glycosylation and deglycosylation for different conformers with models Res16-Qand Res23-Q based on 4C4C. 